OPEN ACCESS

Edited by:

Marijn Lijffijt,

Baylor College of Medicine,

United States

Reviewed by:

Marvin Rafael Diaz,

Binghamton University, United States

Kurt Leroy Hoffman,

Autonomous University of

Tlaxcala, Mexico

${ }^{*}$ Correspondence:

Amir Garakani

amir.garakani@yale.edu

Specialty section:

This article was submitted to

Psychopharmacology,

a section of the journal

Frontiers in Psychiatry

Received: 17 August 2020 Accepted: 13 November 2020 Published: 23 December 2020

Citation:

Garakani A, Murrough JW, Freire RC,

Thom RP, Larkin K, Buono FD and Iosifescu DV (2020) Pharmacotherapy

of Anxiety Disorders: Current and

Emerging Treatment Options.

Front. Psychiatry 11:595584.

doi: 10.3389/fpsyt.2020.595584

\section{Pharmacotherapy of Anxiety Disorders: Current and Emerging Treatment Options}

\author{
Amir Garakani 1,2,3*, James W. Murrough ${ }^{1,4}$, Rafael C. Freire ${ }^{5}$, Robyn P. Thom ${ }^{6}$, \\ Kaitlyn Larkin ${ }^{3}$, Frank D. Buono ${ }^{3}$ and Dan V. losifescu ${ }^{7,8}$
}

${ }^{1}$ Department of Psychiatry, Icahn School of Medicine at Mount Sinai, New York, NY, United States, ${ }^{2}$ Silver Hill Hospital, New Canaan, CT, United States, ${ }^{3}$ Department of Psychiatry, Yale University School of Medicine, New Haven, CT, United States, ${ }^{4}$ Department of Neuroscience, Icahn School of Medicine at Mount Sinai, New York, NY, United States, ${ }^{5}$ Department of Psychiatry and Centre for Neuroscience Studies, Queen's University, Kingston, ON, Canada, ${ }^{6}$ Department of Psychiatry, Massachusetts General Hospital, Harvard Medical School, Boston, MA, United States, ${ }^{7}$ Clinical Research Division, Nathan Kline Institute for Psychiatric Research, Orangeburg, NY, United States, ${ }^{8}$ Department of Psychiatry, New York University School of Medicine, New York, NY, United States

Anxiety disorders are the most prevalent psychiatric disorders and a leading cause of disability. While there continues to be expansive research in posttraumatic stress disorder (PTSD), depression and schizophrenia, there is a relative dearth of novel medications under investigation for anxiety disorders. This review's first aim is to summarize current pharmacological treatments (both approved and off-label) for panic disorder (PD), generalized anxiety disorder (GAD), social anxiety disorder (SAD), and specific phobias (SP), including selective serotonin reuptake inhibitors (SSRIs), serotonin norepinephrine reuptake inhibitors (SNRIs), azapirones (e.g., buspirone), mixed antidepressants (e.g., mirtazapine), antipsychotics, antihistamines (e.g., hydroxyzine), alpha- and beta-adrenergic medications (e.g., propranolol, clonidine), and GABAergic medications (benzodiazepines, pregabalin, and gabapentin). Posttraumatic stress disorder and obsessive-compulsive disorder are excluded from this review. Second, we will review novel pharmacotherapeutic agents under investigation for the treatment of anxiety disorders in adults. The pathways and neurotransmitters reviewed include serotonergic agents, glutamate modulators, GABAergic medications, neuropeptides, neurosteroids, alpha- and beta-adrenergic agents, cannabinoids, and natural remedies. The outcome of the review reveals a lack of randomized double-blind placebo- controlled trials for anxiety disorders and few studies comparing novel treatments to existing anxiolytic agents. Although there are some recent randomized controlled trials for novel agents including neuropeptides, glutamatergic agents (such as ketamine and d-cycloserine), and cannabinoids (including cannabidiol) primarily in GAD or SAD, these trials have largely been negative, with only some promise for kava and PH94B (an inhaled neurosteroid). Overall, the progression of current and future psychopharmacology research in anxiety disorders suggests that there needs to be further expansion in research of these novel pathways and larger-scale studies of promising agents with positive results from smaller trials.

Keywords: anxiolytic, phobia, panic, agoraphobia, psychopharmacology, experimental 


\section{INTRODUCTION}

Anxiety disorders are the most common class of psychiatric disorders, with a lifetime prevalence in the United States of around 32\%, according to the National Comorbidity Survey Replication (NCS-R) (1). Among the anxiety disorders, social anxiety disorder (SAD) and specific phobia (SP) are the most common (1). According to the World Health Organization, there are about 264 million people globally who suffer from anxiety disorders, representing a 15\% increase since 2005 (2). Anxiety can lead to work and school absences and have a larger cost burden than other psychiatric disorders due to their higher prevalence (3-5). Despite this, there has been far less recent research on novel medication treatments for anxiety disorders over the past 5-10 years compared to the number of experimental drug trials on treatments for major depressive disorder (MDD), bipolar disorder, and schizophrenia (www.clinicaltrials.gov).

Part of the reason for the relative paucity of new drug compounds may be the existence of Food and Drug Administration (FDA)-approved efficacious medications and psychotherapies for anxiety disorders, as well as the perception that anxiety disorders are managed adequately with the currently available treatments. The literature, however, indicates that only $60-85 \%$ of patients with anxiety disorders respond (experience at least a $50 \%$ improvement) to current biological and psychological treatments (6). In addition, only about half of the responders achieve recovery (defined as minimal anxiety symptoms) (6). There is also evidence to suggest that patients with anxiety disorders, in particular generalized anxiety disorder (GAD) and SAD (7), have high rates of recurrence and/or experience persistent anxiety symptoms, especially if they have comorbid MDD (8). There could be several explanations for the potential refractory nature of these disorders, including misdiagnosis, poor adherence to treatment, substance use, or other comorbidities, although it does suggest that conventional treatments may not be effective for all patients and alternative pharmacotherapies should be developed (9). Unfortunately, many of the treatments that are currently being investigated are simply modifications of already approved treatments.

The nosology of anxiety disorders underwent a shift with the publication of the Fifth Edition of the Diagnostic and Statistical Manual of Mental Disorders (DSM-5) in 2013 (10). Due to questions about the phenomenological and neurobiological bases of the diseases, both posttraumatic stress disorder (PTSD) and obsessive-compulsive disorder (OCD) were removed from Anxiety Disorders section and placed into their own diagnostic classes. Selective mutism and separation anxiety disorder were also added to the Anxiety Disorders section of the DSM-5. Agoraphobia was separated from and is now a disorder distinct from panic disorder (PD). Given the extensive research done separately on OCD and PTSD and their potentially divergent neurobiochemical pathways and heritability (11), this review will focus on the following DSM-5 Anxiety Disorders: PD, GAD, SAD, and SP. For a thorough review that includes both anxiety disorders and OCD and PTSD, please see Sartori and Singewald (12). Finally, although there is strong evidence for the use of psychotherapies including cognitive behavioral therapy
(CBT) and exposure therapy for anxiety disorders, as well as emerging data for the role of neurostimulation strategies such as transcranial magnetic stimulation (TMS), this review will only consider pharmacotherapies. Additionally, this review will only discuss the treatment of anxiety in adults and will exclude research on children and adolescents. Ongoing clinical studies identified on the Clinical Trials database (www.clinicaltrials.gov) will be cited by their National Clinical Trial (NCT) number.

\section{CURRENT TREATMENTS FOR ANXIETY DISORDERS}

\section{Serotonergic/Norepinephrinergic Antidepressants}

The Food and Drug Administration (FDA) has approved several selective serotonin reuptake inhibitors (SSRIs) and serotonin norepinephrine reuptake inhibitors (SNRIs) for PD, GAD, and SAD. Despite these classifications, medications not approved for a condition are commonly used "off-label" in clinical practice. The European Union has similar indications for the use of SSRIs and SNRIs for the treatment of anxiety disorders as the FDA but with broader indications of SSRIs (12). See Table 1 for a list of FDA-approved and off-label medications for anxiety.

Selective serotonin reuptake inhibitors and SNRIs are both first-line treatments for PD, GAD, and SAD and have been shown to be efficacious for the treatment of anxiety disorders (13-16). A recent meta-analysis reported that most SSRIs and SNRIs are more efficacious than placebo in GAD, with escitalopram and duloxetine potentially having the largest effect sizes (17). The recommended duration of treatment can vary but may be as short as 3-6 months, or up to 1-2 years or even longer. Although there may be concern about tachyphylaxis, there is limited evidence of adverse outcomes with the chronic use of SSRIs or SNRIs (18). These medications also tend to be well-tolerated, with usually manageable or short-lived adverse effects such as nausea, headache, dry mouth, diarrhea, or constipation. Sexual dysfunction tends to be a more durable and problematic adverse effect of SSRIs and SNRIs but can be managed with adjunctive treatments. There is the possibility of patients developing antidepressant-induced jitteriness or anxiety, potentially due to initial surge of serotonin, although this anxiety can be mitigated by slower titration or adjunctive use of benzodiazepines (19).

The tricyclic antidepressants (TCAs), which act as reuptake inhibitors of serotonin and norepinephrine transporters, were one of the first classes of medications used for anxiety disorders (20). Despite comparable efficacy to SSRIs, they are now less frequently prescribed due to concerns about side effects including weight gain, dry mouth, sedation, urinary hesitancy or retention, arrhythmias, and risk of mortality with overdose (20). Clomipramine and imipramine (both TCAs) are FDA-approved for PD. Monoamine oxidase inhibitors (MAOIs) are also older antidepressant medications which are now typically used only as a third-line option because of side effects and dietary restrictions. They are not FDA-approved for anxiety disorders but may be considered in patients with SAD who are non-responsive to SSRIs (21). 
TABLE 1 | Current treatments for anxiety disorders.

\begin{tabular}{|c|c|c|c|c|}
\hline Medication class & Mechanism of action & $\begin{array}{l}\text { FDA approvals for } \\
\text { anxiety disorder }\end{array}$ & Off-label uses & $\begin{array}{l}\text { Therapeutic dose ranges } \\
\text { (mg/day) }\end{array}$ \\
\hline \multicolumn{5}{|l|}{ SSRIs: } \\
\hline Fluoxetine & Selective 5-HT reuptake inhibitor & $\mathrm{PD}$ & GAD, SAD & $20-60$ \\
\hline Sertraline & $(20)$ & $P D, S A D$ & GAD & 50-200 \\
\hline Citalopram & & None & GAD, PD, SAD & $20-40$ \\
\hline Escitalopram & & GAD & $\mathrm{PD}, \mathrm{SAD}$ & $10-20$ \\
\hline Paroxetine & & PD, SAD, GAD & None & $20-60$ \\
\hline Paroxetine ER & & PD, SAD & GAD & $27-75$ \\
\hline Fluvoxamine & & None & GAD, PD, SAD & $100-300$ \\
\hline \multicolumn{5}{|l|}{ SNRIs: } \\
\hline Duloxetine & 5-HT, NE (and DA) reuptake & GAD & PD, SAD & $30-60$ \\
\hline Venlafaxine (XR) & inhibitor (17) & GAD & $\mathrm{PD}, \mathrm{SAD}$ & $75-300$ \\
\hline Desvenlafaxine & & None & GAD, PD, SAD & $50-100$ \\
\hline \multicolumn{5}{|l|}{ TCAs: } \\
\hline Clomipramine & NE and 5-HT reuptake inhibitor (20) & None & GAD, PD, SAD & $100-250$ \\
\hline Imipramine & & None & GAD, PD, SAD & $100-300$ \\
\hline Desipramine & & None & GAD, PD, SAD & $100-200$ \\
\hline Nortriptyline & & None & GAD, PD, SAD & $50-150$ \\
\hline \multicolumn{5}{|l|}{ MAOls: } \\
\hline Phenelzine & MAO inhibitor (21) & None & GAD, PD, SAD & $30-90$ \\
\hline \multicolumn{5}{|c|}{ Mixed antidepressants: } \\
\hline Mirtazapine & $\begin{array}{l}\text { 5-HT } 2,5-\mathrm{HT}_{3}, \alpha_{2}, \mathrm{H}_{1} \text { antagonist } \\
(27)\end{array}$ & None & Anxiety, GAD, PD, SAD & $15-45$ \\
\hline \multicolumn{5}{|l|}{ GABAergic drugs: } \\
\hline $\begin{array}{l}\text { Pregabalin } \\
\text { Gabapentin }\end{array}$ & $\begin{array}{l}\text { Unclear, may modulate Ca channels } \\
(51)\end{array}$ & $\begin{array}{l}\text { None } \\
\text { None }\end{array}$ & $\begin{array}{l}\text { GAD, SAD } \\
\text { GAD, SAD, PD }\end{array}$ & $\begin{array}{l}150-600 \\
600-2,400\end{array}$ \\
\hline \multicolumn{5}{|l|}{ Benzodiazepines: } \\
\hline Clonazepam & GABA-A agonist (44) & $\mathrm{PD}$ & Anxiety, GAD, PD, SAD & $1-2$ \\
\hline Alprazolam & & Anxiety, PD & GAD, PD, SAD & $1-4$ \\
\hline Lorazepam & & Anxiety & GAD, PD, SAD & $2-6$ \\
\hline Chlordiazepoxide & & Anxiety & GAD, PD, SAD & $20-100$ \\
\hline Oxazepam & & Anxiety & GAD, PD, SAD & $30-60$ \\
\hline \multicolumn{5}{|l|}{ Antipsychotics: } \\
\hline Trifluoperazine & $\mathrm{D}_{2}$ antagonist $(84)$ & Anxiety & GAD, PD, SAD & $2-6$ \\
\hline Olanzapine & $\mathrm{D}_{2}, 5-\mathrm{HT}_{2} \mathrm{H}_{1}$ antagonist (85) & None & Anxiety, GAD & $5-15$ \\
\hline Quetiapine & $\mathrm{D}_{2}, 5-\mathrm{HT}_{2} \mathrm{H}_{1}$ antagonist (85) & None & Anxiety, GAD & $50-300$ \\
\hline \multicolumn{5}{|l|}{ Beta-blockers: } \\
\hline Propranolol & $\beta-1, \beta-2$ antagonist (77) & None & Anxiety, PD, SAD & $60-120$ \\
\hline \multicolumn{5}{|l|}{ Antihistamines: } \\
\hline Hydroxyzine & $\mathrm{H}_{1}$ antagonist (76) & Anxiety & GAD, PD, SAD & $25-100$ \\
\hline \multicolumn{5}{|l|}{ Other anxiolytics: } \\
\hline Buspirone & 5- $\mathrm{HT}_{1 \mathrm{~A}}$ partial agonist (22) & Anxiety & GAD & $15-60$ \\
\hline
\end{tabular}

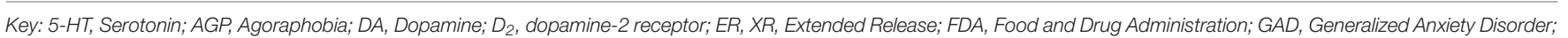

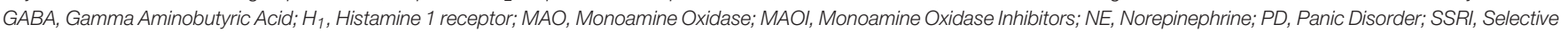
Serotonin Reuptake Inhibitor; SNRI, Serotonin Norepinephrine Reuptake Inhibitor; SAD, Social Anxiety Disorder; TCA, Tricyclic Antidepressants.

Buspirone, a $5-\mathrm{HT}_{1 \mathrm{~A}}$ partial agonist classified under the azapirones, is FDA-approved for use in anxiety, and is commonly used as an adjunctive treatment with SSRIs or SNRIs primarily for GAD (22). It is the only azapirone currently approved in the United States. A Cochrane review of buspirone for GAD found that it was superior to placebo but had a smaller effect size in GAD compared to benzodiazepines and antidepressants (22). Moreover, it was not as well-tolerated (nausea and dizziness) and less effective in those with past benzodiazepine use (22). A subsequent Cochrane review compared buspirone to placebo for PD and found buspirone to be less efficacious than placebo but the review was limited by the dearth of high-quality studies (23). Buspirone is generally dosed two to three times a day and has a gradual onset of action of around 10 days to 4 weeks. Adverse effects include nausea, dizziness, and headache, and there are reports of buspirone-induced movement disorders (24). There is also anecdotal reporting for using buspirone to offset sexual side effects from SSRIs but there are few studies offering empirical support of this practice $(25,26)$. 


\section{Mixed Antidepressants}

Mirtazapine has a broad pharmacological effect, with presynaptic antagonism of the alpha-2 adrenergic receptor, postsynaptic blockade of $5-\mathrm{HT}_{2}$ and $5-\mathrm{HT}_{3}$ receptors, and antagonism of histamine-1 $\left(\mathrm{H}_{1}\right)$ receptors (27). Mirtazapine is FDA-approved for the treatment of MDD in adults. Its benefits include positive effects on sleep and appetite and its general safety for elderly patients, fewer drug-drug interactions, and less likelihood of sexual side effects compared to SSRIs and SNRIs. Adverse effects include weight gain and other antihistamine effects like sedation and dry mouth. There are very few clinical trials assessing mirtazapine for anxiety disorders. In PD, one small randomized controlled trial (RCT) reported that mirtazapine was comparable in efficacy to escitalopram (28). In SAD, one RCT of women showed a significant improvement in anxiety symptoms compared to placebo (29), while a subsequent study failed to show separation from placebo (30). There are no controlled studies of mirtazapine in GAD to date. Overall, in the absence of further trials, the evidence has suggested that mirtazapine may have efficacy in improving anxiety but primarily as an adjunctive agent.

Bupropion is a dopamine norepinephrine reuptake inhibitor approved for the treatment of MDD, attentiondeficit/hyperactivity disorder (ADHD), and smoking cessation (31). Although bupropion has been used in patients with anxiety who are being treated with SSRIs as an adjunct to offset sexual side effects, there has been limited investigation of this medication as a monotherapy for anxiety. Although there is a common perception that bupropion can worsen anxiety, this may not be entirely accurate based on previous research of bupropion on anxiety symptoms in MDD when compared to SSRIs (31-33). To date, there is only one controlled trial of bupropion in anxiety disorders, a RCT comparing bupropion XL to escitalopram in GAD, which found that the two drugs had comparable anxiolytic efficacy (34). The evidence regarding efficacy of bupropion for the treatment of PD is conflicting $(35,36)$. Further work is needed to determine if bupropion and similar dopamine-enhancing agents are efficacious for the treatment of anxiety disorders.

Nefazodone, a serotoninergic modulating antidepressant thought to inhibit 5-HT reuptake and block postsynaptic 5- $\mathrm{HT}_{2}$ receptor (37), is only FDA-approved for the treatment of MDD. There have been several open-label studies suggesting potential benefit in PD and GAD but no controlled studies have been conducted (37-40). One RCT of nefazodone in SAD did not report separation from placebo (41). Overall, its use has been limited by concerns related to very rare but severe cases of liver toxicity.

\section{Gamma Aminobutyric Acid (GABA)}

Benzodiazepines have been a longstanding treatment for anxiety and are still among the most widely prescribed class of psychiatric medications in the world $(42,43)$ although there has been increasing stigma surrounding the use of benzodiazepines in clinical practice (44). Critics of benzodiazepines cite their being prescribed as first-line treatments for anxiety in primary care settings before SSRIs, potential risks of tolerance, dependence, abuse or misuse, and concerns about falls in the elderly (45). However, there is a lack of strong evidence that SSRIs and other first-line treatments are superior to, or better-tolerated than, benzodiazepines for anxiety disorders, in particular GAD (46), especially for short-term treatment $(44,47)$, and possibly beyond 8 weeks as well (48). Benzodiazepines, which act as GABA-A agonists, are highly versatile medications that can be prescribed for a wide range of conditions including alcohol withdrawal, agitation or aggression, anesthesia, catatonia, mania, insomnia, muscle spasms, epilepsy or seizures, and REM sleep behavior and movement disorders (44). Although some reports suggest a potential risk of dementia associated with the chronic use of benzodiazepines, these have been called into question and it appears there is not an increased risk of neurocognitive disorders (49). Benzodiazepines are no longer considered firstline monotherapy for PD or other anxiety disorders but can be used in the short-term on either a standing or as-needed basis for PD, GAD, and SAD in conjunction with SSRIs and SNRIs (Table 1) (14-16). Caution is needed in children, geriatric patients, those with medical comorbidities, and individuals with substance use disorders, especially those using other central nervous system depressants like opioids and/or alcohol. Additionally, chronic use of benzodiazepines to treat anxiety with comorbid depression may result in reduced efficacy of antidepressants (50).

Anticonvulsants, some of which have GABAergic properties, include medications like pregabalin, gabapentin, tiagabine, lamotrigine, and topiramate. There is scant research on the use of this class of medications for anxiety disorders (51), with the strongest evidence for the use of pregabalin in GAD, including a meta-analysis of multiple RCTs reporting superiority to placebo and comparable effects to benzodiazepines (52). Pregabalin is thought to have anti-epileptic effects by its activity on the alpha2 delta subunit of calcium channels to reduce neurotransmitter release (51). Pregabalin has FDA approvals for neuropathic pain, post-herpetic neuralgia, fibromyalgia, and as an adjunctive treatment for partial seizures. It was approved for GAD by the European Union in 2006, although since it was not approved by the FDA in the United States in 2009 the FDA application was withdrawn in 2010. Pregabalin was also shown to have potential efficacy in SAD (53), but only at doses of 450 or $600 \mathrm{mg}$, based on three randomized, double-blind, placebo-controlled trials (5456). Pregabalin is generally well-tolerated, with the most common adverse effects being sedation, dizziness, and weight gain. Since there is the potential for abuse and dependence with pregabalin, it is listed as a Schedule V medication by the United States Drug Enforcement Administration (DEA), and providers need to be mindful of tapering the medication to prevent withdrawal, and to monitor prescribing in patients with substance use problems, especially opioids, for which there is an increased risk of overdose death (57-59).

Gabapentin, much like pregabalin, acts to modulate neurotransmitter release on voltage-dependent calcium channels (51). It is FDA-approved for the treatment of neuropathic pain, post-herpetic neuralgia, and partial seizures, but has been widely used off-label for various indications including fibromyalgia. There is increasing evidence for its use in alcohol use disorder, 
primarily for the treatment of withdrawal (60). Gabapentin has also been prescribed off-label for anxiety despite a lack of research evidence supporting such use (61). It was found to be efficacious in a small $(N=69)$ randomized, double-blind, placebo-controlled study in SAD (62). Another RCT of patients with $\mathrm{PD}$ found a difference between gabapentin and placebo but only in patients with severe panic symptoms (62). A third study found that gabapentin may help with anxiety related to public speaking (63). There are also several trials of gabapentin showing efficacy in perioperative anxiety (61). Gabapentin has similar adverse effects as pregabalin including sedation, dry mouth, constipation, weight gain, and pedal edema. Although gabapentin is not listed as a DEA controlled substance in the US, it may vary on how it is scheduled between states, and there is, like pregabalin, a risk of withdrawal and abuse potential, meaning caution must be used when prescribing this medication to patients taking opioids or those with substance use disorders $(57,59,64)$. There are currently no known ongoing trials of gabapentin for anxiety disorders.

Another anticonvulsant, tiagabine, is FDA-approved for the treatment of partial seizures and has been shown to have potential anxiolytic effects in preclinical studies (65). Its mechanism of action is unknown, although it is thought to increase GABA activity by inhibiting GABA uptake in presynaptic neurons (51). While there have been promising open-label studies for PD, GAD, and PTSD (51), several RCTs do not support the efficacy of tiagabine in GAD (66) or PD (67). A small, randomized, doubleblind crossover study with gabapentin and tiagabine in SAD reported that both drugs may be effective in reducing anxiety scores (68). There are no known active studies of tiagabine in anxiety disorders.

Lamotrigine is an anticonvulsant thought to inhibit voltagedependent sodium channels causing decreased glutamate release (51). It is FDA-approved for the maintenance treatment of bipolar I disorder and for several types of seizure disorders. Lamotrigine was shown to have anxiolytic properties in preclinical studies (69). There are, however, very few studies of lamotrigine in anxiety disorders. One small case series reported improvement in symptoms in $\mathrm{PD}$ with agoraphobia (70). To date, no studies of lamotrigine for anxiety disorders are underway. Other anticonvulsants, like topiramate (thought to inhibit voltage-dependent calcium sodium channels to enhance GABA, block glutamate and inhibit carbonic anhydrase) have very limited data (51), mostly in open-label trials for SAD (71), although there is a trial listed on the Clinical Trials database for topiramate augmentation in treatment-refractory SAD (NCT00182455). There is only one known RCT of valproate, also known as valproic acid (which blocks voltagedependent sodium channels and is thought to increase GABA by inhibiting glutamate-mediated excitation), in which is primarily used to treat bipolar disorder (51). In terms of GAD (72), valproic acid showed separation from placebo, and an open-label trial in SAD suggesting potential efficacy (73). Levetiracetam, approved only for seizure disorders (and with unclear mechanism, but thought to reduce hyperexcitation of brain cells through binding to the synaptic vesicle protein SV2A, but to not interfere with normal electrical activity) (51), has undergone two RCTs for SAD in which the medication failed to show a statistically significant difference compared to placebo $(74,75)$. There are no known RCTs of carbamazepine or oxcarbazepine in anxiety disorders.

\section{Antihistamines}

Hydroxyzine is the most studied antihistamine for anxiety and the only antihistamine which is FDA-approved for use in anxiety. Antihistamines like hydroxyzine are histamine-1 receptor $\left(\mathrm{H}_{1}\right)$ blockers that are commonly used as alternatives to benzodiazepines for anxiety, panic attacks, and insomnia, in both inpatient and outpatient settings (76). Hydroxyzine and other antihistamines like diphenhydramine may also be safer to use in children and adolescents and in pregnant women. There is, however, concern about the risk of anticholinergic toxicity or delirium in the elderly or patients with neurocognitive disorders. Antihistamines are generally well-tolerated, aside from adverse effects like dry mouth, constipation, sedation, and risks of use while driving. The primary drawback to this medication class is that patients tend to develop tolerance to antihistamines over time. A Cochrane review of 39 studies of GAD reported that hydroxyzine was superior to placebo and comparable to benzodiazepines and buspirone but the authors cited a high risk of study bias and concerns about sedation with hydroxyzine (76). To date, there have not been RCTs of hydroxyzine done in SAD and PD.

\section{Alpha- and Beta-Adrenergic Agents}

Propranolol is a beta-adrenergic antagonist that is FDA-approved for multiple indications including hypertension, angina, atrial fibrillation and arrhythmias, migraine prophylaxis, and essential tremor (77). Although it is not approved for any psychiatric indications, it has been widely prescribed for SAD and performance anxiety. There is, however, a lack of research support for the use of propranolol in anxiety disorders (77) although it may still have a role in certain task-specific anxieties (78). Evidence for the use of other beta-blockers like pindolol in anxiety is sparse.

Clonidine and guanfacine are alpha-2 adrenergic receptor agonists FDA-approved for the treatment of hypertension (79, 80 ). Extended-release formulations of guanfacine and clonidine are also approved for ADHD in children and adolescents and clonidine is also approved for adjunctive use of cancer pain and is used off-label for management of opioid withdrawal. Clonidine has been studied previously as a research drug on the noradrenergic system in GAD and PD but was not found to have much utility in clinical settings $(79,81,82)$. There have been no further RCTs of clonidine in anxiety disorders other than studies of the drug as pre-medication for children for preoperative anxiety (83). Both clonidine and guanfacine may have limited practical use in anxious patients given the lack of proven efficacy and concerns about hypotension and sedation.

\section{Antipsychotics}

There is currently only one antipsychotic, trifluoperazine, a first-generation antipsychotic (FGA), which is FDA-approved for the treatment of anxiety. In spite of this, antipsychotics, most of which are dopamine- $2\left(D_{2}\right)$ receptor antagonists, have 
been utilized on an off-label basis for multiple indications other than psychosis including anxiety (84). Several systematic reviews of antipsychotics in anxiety have reported that the majority of studies were of quetiapine, a second-generation antipsychotic (also with antagonism of the $5-\mathrm{HT}_{2}$ and $\mathrm{H}_{1}$ receptors), in GAD, and showed the potential utility of quetiapine monotherapy in GAD despite poor tolerability (85, 86). The Canadian guidelines for anxiety and related disorders recommend olanzapine $\left(\mathrm{D}_{2}, 5-\mathrm{HT}_{2}\right.$ and $\mathrm{H}_{1}$ antagonist), aripiprazole (a partial $\mathrm{D}_{2}$ and $5-\mathrm{HT}_{1 \mathrm{~A}}$ agonist and $5 \mathrm{HT}_{2} \mathrm{~A}$ antagonist) and risperidone $\left(\mathrm{D}_{2}\right.$, and $5-\mathrm{HT}_{2}$ antagonist), as augmentation strategies for GAD and PD (87). Risperidone and aripiprazole are also recommended as adjunctive drugs in the treatment of SAD (87). There is reasonable concern about the short- and long-term risks of using antipsychotics in anxiety disorders. First, there are limited studies to date in other anxiety disorders such as SAD and PD $(85,88)$. Second, it is unclear whether patients receive appropriate psychoeducation about the risks of tardive dyskinesia, extrapyramidal symptoms, neuroleptic malignant syndrome, weight gain, and metabolic syndrome. Further large-scale research and longitudinal studies of antipsychotics in anxiety are needed before these medications can be recommended.

\section{NOVEL TREATMENTS FOR ANXIETY DISORDERS}

The focus of research on the pharmacotherapy of anxiety disorders has shifted from serotonin, norepinephrine and GABA systems to other neurotransmitters and pathways including glutamate and neuropeptides (89). Presented below is a review of recent and ongoing studies of medications for GAD, PD, and SAD. A summary of the findings is on Table 2.

\section{Serotonergic Agents}

The serotonin [5-hydroxytryptamine (5-HT)] system has been studied extensively in the etiology of anxiety and anxiety disorders, and the primary first-line pharmacotherapeutic agents for anxiety are serotonergic, including SSRIs, SNRIs, and azapirones like buspirone. There has been work on developing agents that work on several 5-HT receptors and may mimic the effects of SSRIs but with more favorable side effect profiles. For example, vilazodone, listed as an SSRI while also having partial agonistic properties on $5-\mathrm{HT}_{1 \mathrm{~A}}$, was approved by the FDA for the treatment of MDD in 2011 and it also has been studied in GAD and SAD (90). A meta-analysis of vilazodone for GAD reported that three 10-week RCTs that found a separation from placebo (90) but a later meta-analysis did not support the use of vilazodone in GAD (91). There was also a small pilot randomized, placebo-controlled trial of vilazodone in adult separation anxiety disorder which did not show significant separation between drug and placebo at 12 weeks but reported some differences in other anxiety measures (92). There has been one randomized, double-blind, placebo-controlled trial of vilazodone in SAD which showed potential efficacy and promise (93) and another study listed as active but not recruiting (NCT01712321). There are no known studies, active or recruiting, of vilazodone in PD. Vilazodone may confer benefits over SSRIs, including a possible lessened risk of sexual dysfunction (94), although gastrointestinal side effects may limit tolerability. Further comparison studies in anxiety disorders are needed.

Vortioxetine, a 5- $\mathrm{HT}_{3}$ antagonist and $5-\mathrm{HT}_{1 \mathrm{~A}}$ agonist, was FDA-approved for MDD in 2013, but its efficacy for anxiety is not clear (95). Despite initial promise in GAD (96, 97), and an initial meta-analysis recommending further study (95), two subsequent meta-analyses failed to show significant efficacy of vortioxetine over placebo in GAD despite fairly good tolerability $(91,98)$ and thus further study and pursuit of FDA approval in GAD was abandoned in 2015. There was one open-label study of vortioxetine in PD reporting improvement in panic symptoms (99) but no known RCTs. There is one study in SAD comorbid with MDD underway (NCT04220996), but no studies of vortioxetine in other anxiety disorders.

As noted above, buspirone has been FDA-approved for the treatment of anxiety, which led to the consideration of other azapirones (100). Gepirone, an azapirone and a selective 5$\mathrm{HT}_{1 \mathrm{~A}}$ receptor partial agonist, in its extended-release (ER) form, has been studied previously as an antidepressant, although it has been shown to have also anxiolytic properties $(101,102)$. Gepirone ER is currently in Phase 2 trials for GAD, MDD, and hypoactive sexual desire disorder (103). Tandospirone, yet another azapirone studied for depression and anxiety, showed promise in reducing anxiety in patients with anxious depression $(104,105)$. There was one completed trial of tandospirone in GAD but no published results yet (NCT01614041). There are also no recent or active, ongoing studies of other azapirones such as ipsapirone or lesopitron. In terms of non-azapirone $5-\mathrm{HT}_{1 \mathrm{~A}}$ agonists, PRX-00023 was studied in GAD in a RCT and, despite good tolerability, it did not show separation from placebo on endpoint anxiety (106). Additionally, there are other selective 5$\mathrm{HT}_{1 \mathrm{~A}}$ partial agonists, such as TGFK08AA, in development for GAD (89), and TGW00AA (FKW00GA) in Phase 2 studies for GAD and SAD (107).

Some $5-\mathrm{HT}_{6}$ receptor antagonists, such as AVN-101 and AVN-397, have been reported to have anxiolytic properties in animal studies (108). AVN-101 was shown to be safe and welltolerated in Phase 1 studies and is under investigation for Alzheimer's Disease and may have potential for study in anxiety disorders due to its anxiolytic effects (109).

Ondansetron, approved to treat nausea and vomiting, is a selective $5-\mathrm{HT}_{3}$ antagonist that was found to improve anxiety in a small RCT in GAD (110) and an open-label trial in PD (111). There have, however, been no further studies of ondansetron in anxiety disorders, with the only recent and current studies focused on its use in OCD and tic-related disorders.

Agomelatine, a melatonin-1/melatonin-2 agonist and 5$\mathrm{HT}_{2} \mathrm{C}$ receptor antagonist, has been studied more extensively in depression, although it was also found to have anxiolytic properties (112). Based on several RCTs including comparisons with escitalopram (113-117), a meta-analysis of treatments for GAD determined that agomelatine was well-tolerated and potentially efficacious with the caveat of small sample sizes (91). 
TABLE 2 | Novel medication treatments for anxiety disorders.

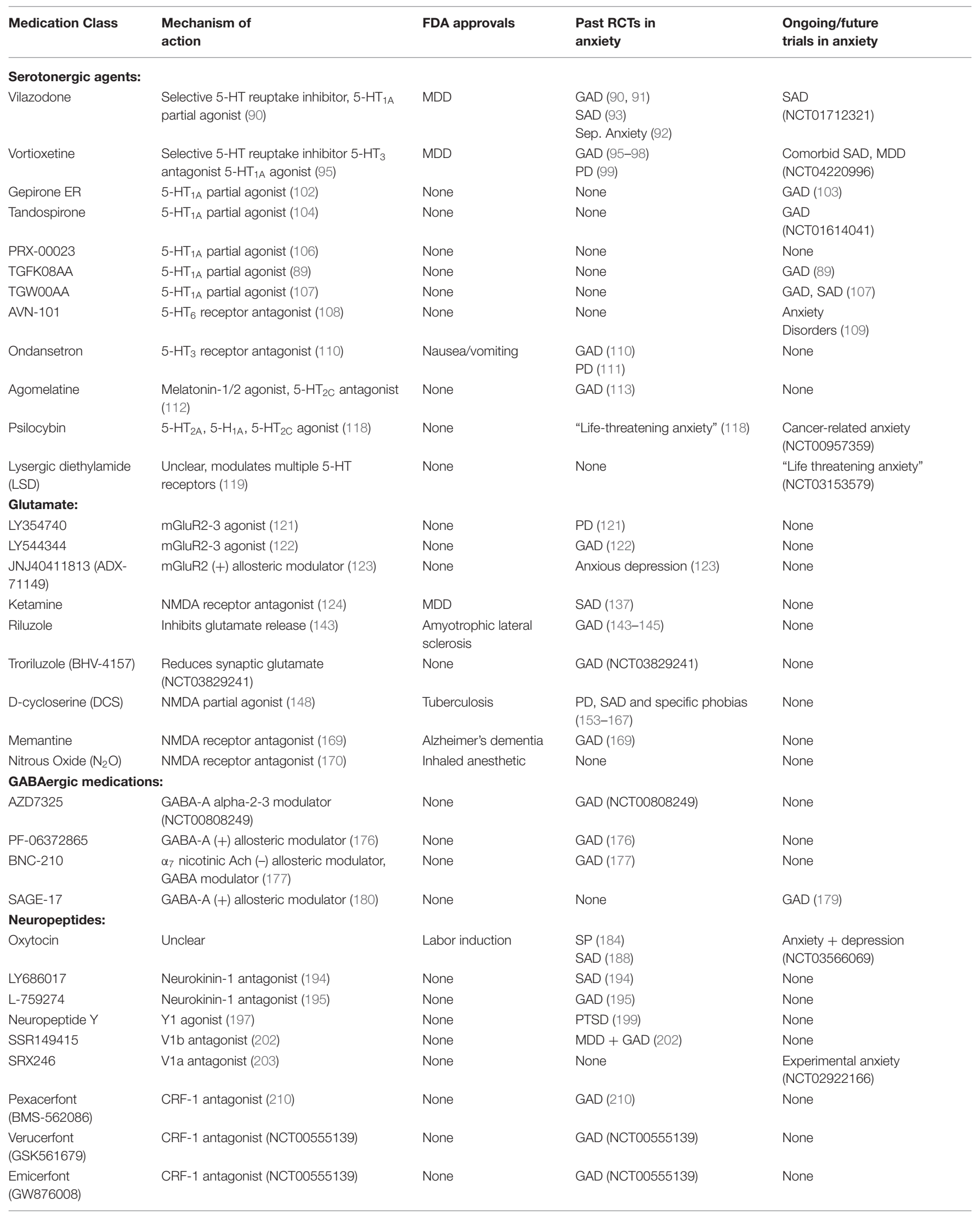


TABLE 2 | Continued

\begin{tabular}{|c|c|c|c|c|}
\hline Medication Class & $\begin{array}{l}\text { Mechanism of } \\
\text { action }\end{array}$ & FDA approvals & $\begin{array}{l}\text { Past RCTs in } \\
\text { anxiety }\end{array}$ & $\begin{array}{l}\text { Ongoing/future } \\
\text { trials in anxiety }\end{array}$ \\
\hline Suvorexant & Orexin 1,2 antagonist (216) & Primary Insomnia & PD (NCT02593682) & None \\
\hline \multicolumn{5}{|l|}{ Neurosteroids: } \\
\hline Mifepristone (RU486) & Progesterone inhibitor (220) & $\begin{array}{l}\text { Early pregnancy } \\
\text { termination }\end{array}$ & $\begin{array}{l}\text { PTSD, GAD, PD or anxiety NOS } \\
(220)\end{array}$ & None \\
\hline PH94B & $\begin{array}{l}\text { Binds to nasal chemosensory receptors to } \\
\text { trigger neural circuits }(221)\end{array}$ & None & $\operatorname{SAD}(221,222)$ & $\begin{array}{l}\text { Adjustment disorder with anxiety } \\
\text { symptoms } \\
\text { (NCT04404192) }\end{array}$ \\
\hline \multicolumn{5}{|l|}{ Cannabinoids: } \\
\hline Cannabidiol (CBD) & $\begin{array}{l}\text { CB1 (-) allosteric modulator, CB2 } \\
\text { antagonist-inverse agonist, } 5 \mathrm{HT}_{1 \mathrm{~A}} \text { agonist } \\
\text { (229) }\end{array}$ & None & $\operatorname{SAD}(26,225,227)$ & $\begin{array}{l}\text { PD, GAD, SAD agoraphobia } \\
\text { (NCT03549819) }\end{array}$ \\
\hline $\begin{array}{l}\text { Delta-9- } \\
\text { tetrahydrocannabinol }\end{array}$ & CB1, CB2 partial agonist (229) & None & None & None \\
\hline Dronabinol & CB1 agonist (229) & $\begin{array}{l}\text { Chemo-related } \\
\text { nausea/vomiting }\end{array}$ & None & None \\
\hline Nabilone & CB1, CB2 agonist (229) & $\begin{array}{l}\text { Chemo-related } \\
\text { nausea/vomiting }\end{array}$ & $\begin{array}{l}\text { GAD, "anxiety neuroses" } \\
(237,238)\end{array}$ & None \\
\hline \multicolumn{5}{|l|}{ Natural remedies: } \\
\hline Kava & $\begin{array}{l}\text { Unclear, activity on } \mathrm{Na} \text {, Ca channels or } \\
\text { GABA-A receptor (244) }\end{array}$ & None & GAD (247) & None \\
\hline Galphimine-B (G-B) & $\begin{array}{l}\text { Unclear, inhibition of DA neurons in ventral } \\
\text { tegmental area (250) }\end{array}$ & None & GAD (250) & $\begin{array}{l}\text { Anxiety } \\
\text { (NCT03702803) }\end{array}$ \\
\hline Chamomile & Unclear, modulates GABA receptors (251) & None & GAD (251) & None \\
\hline Lavender & $\begin{array}{l}\text { Inhibition of voltage-gated Ca channels } \\
\text { (249) }\end{array}$ & None & GAD $(248,249)$ & $\begin{array}{l}\text { Dental anxiety } \\
\text { (NCT04285385) } \\
\text { Pre-operative anxiety } \\
\text { (NCT03445130) }\end{array}$ \\
\hline Saffron & $\begin{array}{l}\text { Unclear, inhibiting } 5 \text {-HT reuptake in } \\
\text { synapses (252) }\end{array}$ & None & Anxiety symptoms (252) & $\begin{array}{l}\text { GAD } \\
\text { (NCT02800733) }\end{array}$ \\
\hline
\end{tabular}

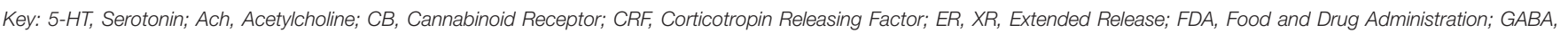

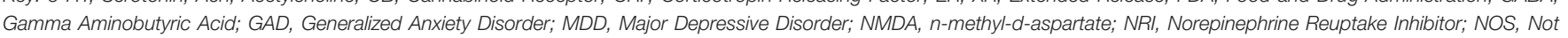

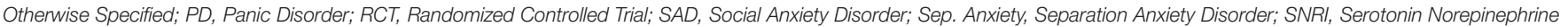
Reuptake Inhibitor; SSRI, Selective Serotonin Reuptake Inhibitor.

Despite its apparent positive response in GAD, there are no known controlled studies of agomelatine in PD or SAD or any known ongoing trials in anxiety disorders.

Finally, it is worthwhile to discuss hallucinogens, which act on serotonin receptors, and their anxiolytic potential. Psilocybin (4phosphoryloxy-N,N-DMT) is an indolealkylamine derived from mushrooms that causes perceptual changes in humans (altered thinking, synesthesia, illusions) and is listed as a DEA Schedule I controlled substance. It has been shown to have the potential to reduce anxiety, with several completed RCTs of psilocybin in cases of "life-threatening anxiety" (patients with anxiety who have life-threatening diseases like cancer) (118). Lysergic acid diethylamide (LSD) is a widely abused hallucinogen with similar effects as psilocybin and is also a Schedule I drug. Prior evidence for the use of LSD in anxiety is less robust and favors its use in alcohol use disorder (119). There is an active clinical trial of psilocybin in cancer-related anxiety (NCT00957359) and a randomized, double-blind, placebo-controlled trial testing LSD in patients with anxiety with or without life-threatening diseases (NCT03153579). The difficulties regulating Schedule I drugs may limit whether hallucinogens have potential for widespread clinical application.

\section{Glutamate Modulators}

Glutamate is the primary excitatory neurotransmitter of the central nervous system. Receptors for glutamate include ionotropic receptors [N-methyl-D-aspartate (NMDA), $\alpha$-Amino-3-hydroxy-5-methyl-4-isoxazolepropionic acid (AMPA)/kainate and metabotropic receptors (mGluR)]. Several preclinical studies have reported anxiolytic effects of mGluR modulators (120), although human studies have not been as promising. For example, LY354740, an mGluR 2-3 agonist, did not separate from placebo in a randomized controlled comparison study with paroxetine (121) in patients with PD. After studies with LY354740 were halted due to concerns about bioavailability, LY544344, a pro-drug of LY354740, was studied for GAD in an 8-week randomized placebo-controlled trial with reported efficacy but the study was halted due to concerns about convulsive activity in preclinical trials (122). JNJ-40411813 (ADX-71149), an mGluR2 positive allosteric modulator, was 
studied in a RCT for anxious depression but did not show efficacy (123).

Ketamine, originally developed as an anesthetic, has shown rapid and robust antidepressant effects in multiple randomized controlled clinical trials. The majority of these studies have tested the safety and efficacy of a single intravenous (IV) infusion of the ketamine in adults with treatment-resistant depression (TRD), most commonly at a dose of $0.5 \mathrm{mg} / \mathrm{kg}$ (124-127). Subsequent studies provide evidence for a favorable safety and efficacy profile of repeated doses of ketamine administered over several weeks (128-130). It should be noted that the use of IV ketamine for TRD is off-label and there is currently a lack of data concerning the longer-term safety and efficacy of this approach $(124,131)$. Ketamine exists as a 1:1 racemic mixture of R-ketamine and S-ketamine. In 2019, an intranasal (IN) form of S-ketamine ("esketamine") gained approval from the FDA for the treatment of MDD in adults with treatment-resistant depression (132). Buoyed by these observations in depression, recent studies have examined the tolerability and potential efficacy of ketamine in anxiety disorders, based on preclinical observations (133).

An early study reported the benefit of daily oral ketamine on symptoms of both depression and anxiety in adults in hospice care (134). A small open-label study suggested benefit of ketamine administered subcutaneously in a single ascending dose design in patients with refractory SAD and/or GAD (135). The same group showed preliminary benefit of ketamine 1 $\mathrm{mg} / \mathrm{kg}$ injected subcutaneously dosed once or twice weekly for 3 months among patients who had responded in the initial ascending dose study (136). More recently, a double-blind RCT of intravenously administered ketamine at $0.5 \mathrm{mg} / \mathrm{kg}$ compared to saline placebo showed benefit in patients with SAD measured using the Liebowitz Social Anxiety Scale (LSAS) (137). There are no known ongoing trials of ketamine in PD, GAD, or SAD.

Riluzole, a glutamate modulator approved for the treatment of amyotrophic lateral sclerosis (ALS), also has been studied previously as an adjunctive agent in TRD (138-140). Animal studies supported the efficacy of riluzole in models of anxiety $(141,142)$. To date, there is only one trial of riluzole in anxiety disorders which was an open-label study of 18 participants with GAD. The trial reported response or remission in a majority of patients, as measured on the Hamilton Anxiety Scale, although the results are limited by the lack of a control group and the small number of participants (143). Subsequent functional neuroimaging studies of open-label riluzole in GAD reported that patients experienced changes in hippocampal volumes and $\mathrm{N}$-acetylaspartate (NAA) concentrations which correlated with improvement on anxiety scales compared with healthy volunteers $(144,145)$. An analog of riluzole, troriluzole (BHV-4157), underwent a Phase III trial in GAD which has been completed although the results have not been published (NCT03829241).

There are several animal studies of AMPA modulators, including PEPA, primarily in fear extinction models of anxiety, showing positive anxiolytic effects (146). One AMPA modulator, Org 26576, has been studied for MDD (147). To date, however, there are no known studies in the pipeline for AMPA modulators for anxiety disorders.
D-cycloserine (DCS), an NMDA partial agonist, is among the most widely studied glutamatergic agents in anxiety (148). Dcycloserine is unique in that research to date has focused on the effects of DCS on anxiety in the context of psychotherapy or fear learning. In animal and human studies, DCS has been shown to facilitate fear extinction (148). Although not known to be efficacious as a monotherapy (149), DCS at a low dose of 50 $\mathrm{mg} /$ day (which is largely an NMDA agonist) has been successfully used in augmentation of exposure therapy or CBT, including reducing anxiety in persons performing cognitive tasks (150) and facilitating declarative learning (151) by reducing reactivity to phobic stimuli in persons with specific phobia on functional MRI (152). D-cycloserine has been studied for augmentation of psychotherapy in PD, SAD, and specific phobias. A 2015 Cochrane review reported no difference between DCS and placebo in augmentation of cognitive and behavioral therapies in anxiety and related disorders at study endpoint or follow up, in both children and adolescents (153). A 2017 metaanalysis of DCS in anxiety disorders found a small difference between DCS and placebo post-treatment but minimal gains on follow-up treatments (154). Subsequent studies of DCS augmentation in PD have been mixed $(155,156)$. In SAD, despite earlier studies showing promise for the use of DCS augmentation of exposure therapy (157-159), there have been far less encouraging findings in subsequent studies $(157,160-$ 162). Studies of DCS in SP, including acrophobia and spider phobia, have yielded inconsistent but mostly negative findings for DCS compared to placebo (163-167). There are no active clinical trials of DCS augmentation in PD, GAD, SAD, or SP. On balance, while initial studies of DCS showed promise for use in augmentation of psychotherapies, subsequent larger-scale studies have been disappointing.

Memantine, an NMDA receptor antagonist FDA-approved for the treatment of Alzheimer dementia, moderate-severe, was tested previously in preclinical studies as a potential antidepressant (168). One study reported minimal improvement in seven patients with GAD, while 10 participants with OCD experienced modest benefit (169). There are no known active studies of memantine for anxiety disorders.

Finally, nitrous oxide $\left(\mathrm{N}_{2} \mathrm{O}\right)$, an inhaled anesthetic most often used in dental procedures, is a NMDA receptor antagonist (170). Nitrous oxide can be used recreationally and has been associated with potential neurologic and psychiatric adverse effects (171). There also has been some study of $\mathrm{N}_{2} \mathrm{O}$ for the treatment of alcohol withdrawal (172) and a proof-of-concept study in MDD (173). Although there is literature on using $\mathrm{N}_{2} \mathrm{O}$ for the treatment of dental phobia and other procedure-related anxiety (174), there is, to date, no known past or current study of $\mathrm{N}_{2} \mathrm{O}$ as a pharmacologic treatment of $\mathrm{PD}, \mathrm{GAD}$, or SAD.

\section{GABAergic Medications}

Given how efficacious benzodiazepines (GABA-A agonists) are for the treatment of anxiety disorders, and how there may be potential benefits with pregabalin and gabapentin, there has been an effort to find novel GABAergic anxiolytic agents. To date, however, several GABA-A receptor subtype agonists have either failed to reach market due to lack of efficacy or poor 
tolerability $(89,175)$. AZD7325, a GABA-A alpha-2-3 modulator, failed to separate from placebo in a Phase 2 comparative trial with placebo and alprazolam for GAD (NCT00808249). PF06372865, a GABA-A positive allosteric modulator, tested at two doses, failed to separate from placebo as an adjunctive treatment in patients with GAD (176). On an encouraging note, BNC210 (IW-2143), an $\alpha 7$ nicotinic acetylcholine receptor-negative allosteric modulator which also modulates the GABA receptor, was reported to result in reduced amygdalar activation to fearful faces compared to placebo and comparably to lorazepam, in patients with GAD (177). Although it is unknown how many GABA modulators are being studied in anxiety, preclinical research suggests that several agents may be in the pipeline (178). For instance, SAGE-217 is a GABA-A positive allosteric modulator that is under Phase III study for MDD and postpartum depression and is being explored for treatment of GAD (179, 180). Finally, phytochemical (herbal) compounds that have GABAergic properties are also under investigation (see "Natural Remedies" section below).

\section{Neuropeptides}

Neuropeptides are small proteins that work as neuronal signaling molecules and are involved in an array of brain functions such as analgesia, reward systems, social behaviors, learning, and memory. In addition, specific neuropeptides such as oxytocin, substance $\mathrm{P}$, neuropeptide Y (NPY), arginine vasopressin (AVP), and cholecystokinin (CCK) play significant roles in modulating fear and anxiety.

Oxytocin is a neuropeptide involved in attachment and prosocial behaviors. Due to its poor absorption in the digestive tract, oxytocin must be administered either intravenously, intranasally or sublingually, where it is well-tolerated with no known serious adverse effects (181). Studies have shown that in healthy adults, oxytocin has positive effects on emotion modulation (182), and that low oxytocin has been associated with high anxiety (183). Animal studies suggest that oxytocin has anxiolytic effects and human research suggests that oxytocin may increase anxiety acutely. For example, a double-blind, placebo-controlled study of intranasal oxytocin on single-session exposure-based psychotherapy for arachnophobia found that oxytocin impaired treatment response compared to placebo (184). Overall, however, oxytocin may have overall positive effects on anxiety depending on the frequency and context of administration (183). Research on oxytocin for the treatment of anxiety disorders has been focused on SAD $(185,186)$, with studies reporting increasing amygdalar-prefrontal activity in response to emotional faces (187), and enhancing prosocial behaviors (188). Although there is a large body of research on the use of oxytocin for augmentation of antipsychotics in schizophrenia (189), several of these trials have been called into question (190) due to study design and sample size and there has been controversy about whether oxytocin can be absorbed into the brain with intranasal administration or if peripheral levels reflect central activity (191). Currently, there is one known study evaluating intranasal oxytocin in patients suffering from acute anxiety and depression during psychiatric hospitalization (NCT03566069).
Substance $\mathrm{P}$ is one of the major neuropeptides found in the nervous system (192). Given its abundance in the fear center of the brain, Substance P and its neurokinin receptor system have been a great topic of interest in anxiety disorder research (193). Despite ample research interest, several trials have failed to demonstrate the efficacy of Substance $\mathrm{P}$ in reducing symptoms of anxiety disorders $(194,195)$, which has led to a decrease in pharmaceutical studies (193). A recent study conducted by Frick et al. (196) however, found that individuals with SAD demonstrated more NK1 receptor availability in the right amygdala when compared to healthy controls. This finding highlights the need for further research on utilizing NK1 receptor antagonists for the treatment of some anxiety disorders. Currently, there are not any ongoing clinical studies that evaluate the use of Substance P for the treatment of anxiety disorders.

Neuropeptide $\mathrm{Y}$ is one of the most abundant neuropeptides in the brain and numerous reports have found that NPY is critical for the stress adaptation process (197). In humans, NPY has been closely linked to trauma. Most recently, a small RCT of intranasally administered NPY in patients with MDD showed potential benefit for depression (198). A study conducted by Sayed et al. found that intranasally administered NPY was associated with greater treatment response and improvement in anxiety ratings when compared to placebo in individuals with PTSD (199). This finding encourages future research that studies the safety and efficacy of NPY as an anxiolytic treatment. There are however no active trials of NPY in GAD, PD, or SAD.

Arginine Vasopressin (AVP) has been shown in animal models to be related to anxiety responses and vasopressin V1a and $\mathrm{V} 1 \mathrm{~b}$ receptor antagonists may have anxiolytic properties (200, 201). Few human studies of V1 antagonists have been published. Griebel et al. (202) compared the vasopressin V1b antagonist, SSR149415, in a randomized, double-blind study, to escitalopram, paroxetine and placebo, in MDD and GAD, reporting that SSR149415 did not differentiate from placebo in outcome measures for GAD. Conversely, studies conducted by Fabio et al. (203), and Lee et al. (204) have shown safety and promise of V1a receptor SRX246 as an anxiolytic, with an active study of this compound in an experimental model of anxiety in humans (NCT02922166). There are currently no known clinical trials studying V1a antagonists in the treatment of anxiety disorders.

Cholecystokinin (CCK) is a peptide which helps regulate gastric secretions and motility and biliary function in the gastrointestinal system; in the brain, CCK is found in the brain's fear network (e.g., the amygdala, hypothalamus, etc.) (205). Current research surrounding CCK is complex in that CCK agonists are panicogenic, but CCK-2 antagonists fail to alleviate human anxiety (206), leaving many unanswered questions regarding the role of CCK in human anxiety. According to clinialtrials.gov, there are currently no known clinical studies evaluating CCK antagonists for the treatment of anxiety disorders.

Corticotropin-releasing factor (CRF) plays a role in stress response and individuals with anxiety disorders exhibit aberrant CRF homeostasis (207). Conversely, CRF receptor antagonists have been shown to have potential anxiolytic effects in 
animal models (208). The results from preliminary research in anxiety disorders, however, have been disappointing (209). One randomized, double-blind trial of the CRF-1 antagonist, pexacerfont (BMS-562086), compared to escitalopram and placebo for the treatment of GAD, found that it did not separate from placebo (210). There are also completed, but not published, studies for SAD comparing CRF-1 antagonists verucerfont (GSK561679) and emicerfont (GW876008) to alprazolam and placebo (NCT00555139), and a Phase 2 trial of patients with GAD comparing GW876008 to paroxetine and placebo (NCT00397722). Research on CRF-1 antagonists appears to have shifted toward addiction with recent trials of pexacerfont and verucerfont in alcohol use disorder $(211,212)$. There are no known active trials of CRF-1 antagonists in anxiety disorders.

Orexin, also known as hypocretin, is a neuropeptide associated with arousal, appetite, and wakefulness (213). Orexin is also thought to play a role in stress response with alterations in orexin found in depression and anxiety (214). Based on the research finding that orexin levels are increased in CSF of individuals with PD (215), orexin is thought to have anxiogenic effects, leading to research on orexin-1 and orexin-2 receptor, and dual-receptor antagonists for treatment of anxiety disorders (216). Suvorexant, an orexin-1 and orexin-2 receptor antagonist, is FDA-approved for primary insomnia, and is under study in $\mathrm{PD}$, comparing the drug to placebo to monitor orexin levels and response to a carbon dioxide challenge (NCT02593682). There are no other known ongoing studies of orexin antagonists in anxiety disorders.

In summary, neuropeptides appear to be a promising emerging field for the treatment of anxiety disorders but there no clear therapeutic candidates for anxiety disorder have been identified as of yet.

\section{Neurosteroids}

Neurosteroids, also known as neuroactive steroids, act as transcription factors to regulate gene expression and endogenously modulate neuronal excitability by interacting with GABA-A, NMDA, and glutamate receptors (217). Both preclinical and clinical studies have demonstrated evidence of aberrant neurosteroid homeostasis in anxiety disorders (218). The antidepressant effects of SSRIs have been shown to correlate with increased brain and cerebrospinal fluid levels of allopregnanolone, a neurosteroid with potent modulatory activity on GABA-A receptors (219). Because of their ability to rapidly control the excitability of the central nervous system, there has been increasing interest in the role of neurosteroids as novel treatments for anxiety disorders. To date, two compounds with neurosteroidal activity, mifepristone (RU486) and PH94B, have been investigated for the treatment of anxiety symptoms.

RU486 is a progesterone inhibitor used for early pregnancy termination (220). It is a glucocorticoid antagonist and has been studied for MDD with psychotic features, improving cognition in patients with bipolar disorder and schizophrenia, and for the treatment of PTSD. A 12-week, pilot clinical trial assessed the effect of mifepristone in older adults as a treatment for anxiety disorders with co-morbid cognitive dysfunction (220). The study included 15 older adults (ages 60 years and older) with an anxiety disorder (GAD, PD, or anxiety disorder not otherwise specified). Subjects were randomized to either mifepristone $300 \mathrm{mg}$ daily or placebo for the first week of the study. After the first week, all patients received treatment with mifepristone $300 \mathrm{mg}$ daily for an additional 3 weeks. At the end of week 4, mifepristone was discontinued, and follow-up assessments of memory, executive function, and anxiety were completed at week 12 . Subjects with higher baseline cortisol levels had improvements in memory, executive function, and anxiety, while those with low or normal baseline cortisol levels experienced little to no mifepristonerelated improvement. There are no active studies of mifepristone in anxiety disorders.

PH94B, an intranasally administered neurosteroidal aerosol, has been investigated for the acute treatment of SAD. In a phase 2, multi-center, randomized, double-blind, placebo-controlled, single-dose study, 91 females (ages 19-60 years) with SAD were randomized to receive either placebo or $\mathrm{PH} 94 \mathrm{~B}$ nasal spray 15 min prior to a public speaking or social interaction challenge under laboratory settings (221). Seventy-five percent of the subjects who received PH94B were considered responders [either "much" or "very much improved" as measured by the Clinical Global Impressions-Improvement (CGI-I)], compared with 37\% of the subjects who received placebo. There were no differences in adverse events reported by the PH94B and placebo groups. A second study assessed the use of PH94B for the treatment of symptoms of SAD in real-world settings in a pilot, randomized, double-blind, placebo-controlled trial (222). Twenty-two males and females (ages 18-65 years) with SAD were randomized to either placebo or PH94 nasal spray. The subjects were instructed to self-administer the nasal spray $15 \mathrm{~min}$ prior to a distressing social interaction or performance, up to four times per day. $\mathrm{PH} 94 \mathrm{~B}$ was superior to placebo in decreasing mean peak levels of symptoms of social anxiety, as measured by subject-reported subjective units of distress (SUDs). The results of an openlabel study of PH94B for the treatment of adjustment disorder with anxiety symptoms in adults which has planned to begin enrollment in 2020 will be of great interest (NCT04404192).

\section{Alpha- and Beta-Adrenergic Agents}

As noted above, clonidine may be used off-label for anxiety but there have been no recent clinical studies of clonidine in anxiety disorders. There are no current drug trials of clonidine in $\mathrm{PD}, \mathrm{SAD}, \mathrm{GAD}$, or SP. One RCT of guanfacine ER in children and adolescents (ages 8-17 years) with GAD, separation anxiety disorder, and SAD reported that the medication was safe and well-tolerated but it is unclear whether it is efficacious (80). To date, there are also no known active studies of guanfacine in anxiety disorders. As noted earlier, there is currently limited active investigation of propranolol for anxiety disorders outside of the extensive research done on memory consolidation and PTSD.

\section{Cannabinoids}

In many parts of the world, cannabis is consumed for its euphoric and relaxing effects. There is a widespread belief that cannabis, cannabidiol (CBD), and other cannabinoids are harmless substances and can lower anxiety and induce 
relaxation. However, the literature does not support the belief that cannabinoids are safe for patients with anxiety disorders, nor does it support the notion that cannabinoids improve anxiety and related symptoms in those patients. The quality of evidence currently available from clinical trials with cannabinoids and anxiety is very low. This is in part because most of the studies included participants with a primary diagnosis of chronic noncancer pain, multiple sclerosis or fibromyalgia, rather than anxiety disorders. Other limitations of these studies include small sample size and other methodological flaws (223).

Endogenous and exogenous cannabinoids act on the cannabinoid type 1 (CB1) receptor, serotonergic type $1 \mathrm{~A}$ $\left(5 \mathrm{HT}_{1 \mathrm{~A}}\right)$ receptor and the transient receptor potential vanilloid type 1 (TRPV1) receptor. Cannabinoid type 1 receptor agonists have a biphasic effect: they have anxiolytic properties in low doses and anxiogenic properties in high doses. While the activation of the CB1 receptor produces inhibitory effect in the neuron, leading to an anxiolytic effect, high doses of CB1 receptor agonists induce activation of TRPV1 receptor, which produces anxiogenic effects (224). Several drugs that act as $5 \mathrm{HT}_{1 \mathrm{~A}}$ receptor agonists proved to be effective in the treatment of anxiety disorders; recent studies indicate that cannabidiol and other cannabinoids also act on the $5 \mathrm{HT}_{1 \mathrm{~A}}$ receptor, potentially resulting in anxiolytic effects (224).

The most studied cannabinoid in anxiety is CBD. Preclinical animal model studies and human trials indicate that $\mathrm{CBD}$ is a potentially effective treatment for PD, GAD, and SAD (224). In the study from Bergamaschi et al. (225), the authors found that the administration of a single dose of CBD $(600 \mathrm{mg})$ successfully attenuated the anxiety response to a public speaking test in subjects with SAD. In another study, the same research team found that a single $400 \mathrm{mg}$ dose of CBD reduced the anxiety associated with a SPECT scan in patients with SAD (226). One small RCT which included 37 adolescents with SAD (CBD $n=17$, placebo $n=20$ ) showed promising results (227). Subjects received $300 \mathrm{mg}$ of CBD or placebo daily for 4 weeks. The Liebowitz Social Anxiety Scale (LSAS) scores decreased by $16 \%(P=0.03)$ pre- and post-treatment in the CBD group. The drug-placebo difference in LSAS was not statistically significant. Currently, there is a RCT with CBD underway (NCT03549819) with an estimated completion date of October 2020. Flexibly dosed CBD (200-800 mg/day) will be administered for 8 weeks to patients with PD, GAD, SAD, or agoraphobia.

Excessive activity in limbic and paralimbic cortical areas has been consistently implicated in the pathophysiology of anxiety disorders. The parahippocampal gyrus and hippocampus are thought to play a key role in mediating fear and anxiety. The public speaking test produces activation of limbic areas in SAD subjects, but in subjects treated with citalopram there is a decreased regional cerebral blood flow ( $\mathrm{rCBF}$ ) response in the amygdala, hippocampus, and the periamygdaloid, rhinal and parahippocampal cortices (228). In the study from Crippa et al. (226) they found that CBD administration decreased resting $\mathrm{rCBF}$ in the limbic area, namely in the left parahippocampal gyrus and hippocampus. Although the effects of citalopram and $\mathrm{CBD}$ were similar in some areas, citalopram produced decreased
$\mathrm{rCBF}$ in the cingulate gyrus, while $\mathrm{CBD}$ produced increased $\mathrm{rCBF}$ in the right posterior cingulate gyrus (226).

The anxiolytic effects observed with CBD are in contrast to the anxiogenic effects induced by delta-9-tetrahydrocannabinol (229). Delta-9-tetrahydrocannabinol (THC) is a partial agonist of the CB1 receptor that can have anxiolytic effect in low doses, but in high doses can induce anxiety and panic attacks (229). In a clinical trial for treatment of Tourette syndrome, the authors found worsening of obsessive-compulsive behavior after the administration of THC. No significant differences were found in anxiety scores, but there was a trend of higher phobic anxiety after administration of THC (230). There are no registered trials for THC in anxiety disorders.

Dronabinol is a synthetic trans isomer of THC and, compared to THC has higher affinity to the CB1 receptor (229). Two RCTs found that dronabinol was effective for treatment for pain, but neither study found significant changes in anxiety scores (231, 232). In the study by Narang et al. two subjects experienced high anxiety as a side effect of a higher dronabinol dose (20 mg) (232). There is one registered study listed as withdrawn (NCT03369639) with dronabinol and anxiety disorders; there are no active studies.

Nabilone is also a synthetic cannabinoid which is similar to but more potent than THC. It has high affinity to CB1 and CB2 receptors. Four studies assessed the effects of nabilone in pain as a primary outcome and anxiety as a secondary outcome (233236). One RCT (233) which included subjects with neuropathic pain demonstrated that nabilone was effective for the treatment of pain but did not produce any changes in anxiety. In the study by Toth et al. 1-4 mg/day of nabilone was effective in relieving pain, improving disturbed sleep, reducing anxiety, and increasing the quality of life of patients with diabetic peripheral neuropathic pain (236). Skrabek et al. (235) also found that nabilone produced improvement of pain, decreased anxiety, and increased quality of life in fibromyalgia patients. In patients with chronic headache, nabilone was more effective than ibuprofen for pain management, but there were no significant differences in anxiety scores (234). In the first of two small clinical trials (237), patients with either GAD or "anxiety neuroses" received placebo or nabilone over four sessions, 7 days apart. Anxiolytic effects were observed only in a small portion of the patients. In another study, 25 patients with anxiety received $2-10 \mathrm{mg} /$ day of nabilone for 28 days and had significant improvement of anxiety in an open-label phase (238). In the RCT phase of the same study, patients received nabilone $3 \mathrm{mg} /$ day for 28 days and the improvement in the nabilone group was superior to the placebo group. Side effects included drowsiness, dry mouth, and dry eyes. Significant improvements in anxiety scores were also noted in a cross-over comparison of nabilone (1-2.5 mg twice daily) and placebo in 11 anxious patients (239). There are currently no registered clinical trials assessing nabilone in anxiety disorders.

Preparations including both THC and CBD (THC-CBD) have been tested as treatments for pain in two RCTs. In two small RCTs which included patients with multiple sclerosis, THC-CBD did not increase or decrease anxiety $(240,241)$. In one of those studies (240), THC-CBD was effective in the treatment of pain and sleep disturbances, while in the second study (241) THC-CBD was not effective for pain. In a RCT 
of THC-CBD for the treatment of Huntington's Disease (242), there were no significant improvements of motor, cognitive, behavioral, and functional scores. Also, there were no significant changes in anxiety scores. There are no registered trials for THC-CBD in anxiety disorders, but there is one trial underway (NCT03491384) assessing the effect of recreational cannabis use on anxiety symptoms.

Regarding the safety of cannabinoids, currently there are no studies showing that $\mathrm{CBD}$ or nabilone increase anxiety or cause panic attacks, suggesting that these medications are safe for patients with anxiety disorders. However, THC and dronabinol are likely not safe drugs for these patients because they can induce anxiety and panic attacks depending on the doses and individual predispositions of each patient. In conclusion, cannabidiol and nabilone are the most promising cannabinoids in the treatment of anxiety disorders, but the level of evidence for these drugs is still very low. Overall, THC, THC-CBD and dronabinol seem to be ineffective and potentially harmful for subjects with anxiety disorders.

\section{Natural Remedies}

There has been increased study of herbal medications for depression and anxiety, with over 30 medications having been tested in some capacity over the past 15 year (243). Despite this burgeoning interest in natural agents, the data for most of them remains sparse. The most widely studied herbal compound is kava, a plant containing kavapyrones, which are thought to exert anxiolytic effects through activity on sodium and calcium channels or most likely from action on GABA-A receptors (like benzodiazepines) (244). A Cochrane meta-analysis of RCTs of kava in anxiety disorders, published in 2003, reported reductions in anxiety scores and separation from placebo (245). A more recent analysis was more conservative and noted that kava could be recommended for short-term use in anxiety but should not replace longer-term medications (246), while another review concluded that, given insufficient evidence, kava could not be recommended for GAD (247). All the above reviews also noted the risk of liver toxicity, including potentially severe liver toxicity, with the use of kava. There are no known active or upcoming studies of kava in anxiety disorders.

Several systematic reviews of other herbal compounds for the treatment of anxiety and anxiety disorders have been conducted and reported including RCTs for several agents such as ashwagandha, passionflower, galphimia, echinacea, ginkgo, chamomile, lemon balm, valerian, and lavender $(243,248,249)$. A recent trial compared Galphimine-B (G-B), isolated from Galphimia (and found in rats to have anxiolytic effect through inhibition of dopaminergic neurons in the ventral tegmental area), to alprazolam, a benzodiazepine, as a control, in patients with GAD and reported that G-B had comparable efficacy to alprazolam with less sedation (250). Although there have been several positive studies of natural treatments for GAD, in particular for chamomile (251), the agent with strongest evidence for use is kava. Currently, there are ongoing clinical trials using lavender (thought to treat anxiety by inhibiting voltage-gated calcium channels) for dental (NCT04285385) and pre-operative anxiety (NCT03445130) and a Phase 2 randomized double-blind trial comparing galphimia to alprazolam for the treatment of anxiety (NCT03702803). Although saffron (Crocus sativus) has been studied for depression and anxiety, due to its possible effects of inhibiting serotonin reuptake in synapses (252), there is only one listed study, a randomized, double-blind RCT in mild to moderate GAD, although its status is unknown (NCT02800733).

\section{DISCUSSION}

Since this group's last review of novel therapies for anxiety disorders in 2014 (253), there has been little headway made in the development or clinical evaluation of new drugs for PD, GAD, and SAD. There have been no new medications approved by the FDA for any anxiety disorder during that time. Although there have been trials of serotonergic agents (like vortioxetine and agomelatine), glutamate modulators (such as riluzole and ketamine), neuropeptides, and even cannabinoids, very few have advanced to Phase III trials or have shown real promise for anxiety disorders. This trend lies in contrast to the greater number of studies taking place for PTSD, OCD, mood/depressive disorders, and schizophrenia. Moreover, the field lacks data contrasting specific drugs (or mechanisms of action) with efficacy, which would be required to propose rational protocols for the selection of optimally efficacious treatments.

The traditional areas of research for anxiety included serotonin, norepinephrine, and GABA, and indeed there are several drugs recently studied and under investigation targeting these neurotransmitters. This research, however, has been built upon the previous success of SSRIs, SNRIs, and GABAergic agents like benzodiazepines, and, to a lesser extent, pregabalin and gabapentin, neither of which are approved in the United States but are prescribed off-label for anxiety. The temptation to continue work on these pathways is due to the acknowledgment that these treatments are effective while failing to expand beyond this comfort zone. Indeed, the neurobiology of anxiety has expanded well beyond the research on fear condition, false suffocation alarms, and the neuroendocrine and HPA-axis models of panic and fear. The early neurocircuitry models of anxiety were based on pre-clinical research and cast a wide net, including PTSD in those models. It is now better understood how much heterogeneity exists between PTSD and other anxiety disorders and even in the class of anxiety disorders, among $\mathrm{PD}, \mathrm{SAD}$, and GAD (11). While neuroimaging studies in the last two decades have led to a refined understanding of brain circuits involved in fear and anxiety, this knowledge has not yet translated in insights leading to novel treatments (with the exception, perhaps, of attempts to use transcranial magnetic stimulation to modulate anxiety and fear circuitry) (254). This is also because in general pharmacotherapies are less clearly related to the functioning of specific brain circuits.

The pursuit of novel pharmacotherapies for anxiety disorders has been fraught with many complications. The first-line treatments, SSRIs and SNRIs, were originally approved for depressive disorders and then later for anxiety disorders. There have been very few drugs developed de novo for anxiety. Studies 
of newer agents have been hampered by flawed study designs such as lack of controls or using placebos instead of comparison to established medications such as SSRIs or benzodiazepines. While this may seem like an insurmountable hurdle, there is hope in that several compounds, including neurosteroids, neuropeptides, and phytochemicals (herbal compounds), have shown some potential. It also would help to study medications specifically for how the disorder manifests clinically, such as how $\mathrm{PH} 94 \mathrm{~B}$ has been investigated for performance anxiety in SAD by being administered $15 \mathrm{~min}$ before the participant is to have a social interaction or give a performance (222). Although study designs may be tricky, studying the use of pro re nata (PRN) or "as-needed" medications may be of more clinical use to patients, especially given that this is how a significant portion of patients are prescribed benzodiazepines.

Therein lies a second area of concern. Although it has been assumed that most patients respond to SSRI or SNRI medications, benzodiazepines, psychological treatments, or some combination, about one-third of these patients have treatmentrefractory anxiety. There is still little known about treatment resistance in anxiety disorders and how to treat it effectively. It also remains unclear how many patients are being treated with effective doses or being given adequate trials or are potentially being misdiagnosed or treated with inappropriate regimens. Anxiety disorders, in addition to their high prevalence, are a leading cause of disability, which is exacerbated by their high comorbidity with depression (255). Naturalistic studies may be needed to understand how to treat anxiety patients with psychiatric, medical, and substance comorbidities.

Perhaps the clearest limitation of this synopsis is the intentional omission of psychotherapies for anxiety disorders. Although their efficacy in PD, GAD, and SAD, has been documented, this review aimed to focus on pharmacotherapies. That said, it is impossible to ignore the importance of therapy-assisted medications such as DCS or potentially even psychedelic medications. Ideally, such medications could reduce the distress related to exposure techniques and enhance the retention of information in anxiety-focused psychotherapy,

\section{REFERENCES}

1. Kessler RC, Chiu WT, Demler O, Merikangas KR, Walters EE. Prevalence, severity, and comorbidity of 12-month DSM-IV disorders in the National Comorbidity Survey Replication. Arch Gen Psychiatry. (2005) 62:61727. doi: 10.1001/archpsyc.62.6.617

2. Depression and Other Common Mental Disorders: Global Health Estimates. Geneva: World Health Organization (2017).

3. Ahola K, Virtanen M, Honkonen T, Isometsä E, Aromaa A, Lönnqvist J. Common mental disorders and subsequent work disability: a population-based health 2000 study. J Affect Disord. (2011) 134:365-72. doi: 10.1016/j.jad.2011.05.028

4. Smit F, Cuijpers P, Oostenbrink J, Batelaan N, de Graaf R, Beekman A. Costs of nine common mental disorders: implications for curative and preventive psychiatry. J Ment Health Policy Econ. (2006) 9:193-200.

5. Alonso J, Angermeyer MC, Bernert S, Bruffaerts R, Brugha TS, Bryson $\mathrm{H}$, et al. Disability and quality of life impact of mental disorders in Europe: results from the European Study of the Epidemiology of Mental Disorders (ESEMeD) project. Acta Psychiatr Scand Suppl. (2004) 2004:3846. doi: 10.1111/j.1600-0047.2004.00329.x ultimately increasing its overall efficacy. Such medications are also important given the lack of access to care and how few patients are in fact being treated first by psychiatrists (for medication management) and can receive appropriate CBT or exposure therapies for their anxiety disorders. This is certainly an area that needs greater investigation. Further research on augmented psychotherapies should not, however, preclude the concomitant development of novel pharmacotherapies, especially given evidence for greater efficacy of pharmacologic treatments over psychological therapies for certain anxiety disorders such as GAD (256).

Since this review did not uncover a wide range of support for promising pharmacotherapies for anxiety disorders in development, we need to reconsider what treatments currently work best, and what areas to focus on going forward. While developing serotonergic or GABAergic agents with more favorable side effect profiles (compared to SSRIs, SNRIs, and benzodiazepines, gabapentin and pregabalin) may have some clinical value, there needs to be further expansion into agents targeting neuropeptide pathways, glutamate, endocannabinoids, and multi-modal medications (including phytochemicals and hallucinogens). These newer compounds may not replace the current treatments but may over time serve as adjuncts or aid in therapy, at least until the field can develop better biomarkers and incorporate brain imaging, pharmacogenomic and other neurobiochemical advances. In terms of pharmacological development, it is time for anxiety disorders to catch up to depression, PTSD, bipolar disorder, and schizophrenia.

\section{AUTHOR CONTRIBUTIONS}

AG, JM, RT, RF, and DI contributed to conception and design and wrote the original draft of the manuscript. AG, JM, RF, RT, KL, FB, and DI contributed to manuscript revisions, review and analysis of the literature, and creation of the tables. All authors reviewed and approved the final draft of the manuscript and made substantial contributions to this study.

6. Bystritsky A. Treatment-resistant anxiety disorders. Mol Psychiatry. (2006) 11:805-14. doi: 10.1038/sj.mp.4001852

7. Rodriguez BF, Weisberg RB, Pagano ME, Bruce SE, Spencer MA, Culpepper L, et al. Characteristics and predictors of full and partial recovery from generalized anxiety disorder in primary care patients. J Nerv Ment Dis. (2006) 194:91-7. doi: 10.1097/01.nmd.0000198140. 02154.32

8. Bruce SE, Yonkers KA, Otto MW, Eisen JL, Weisberg RB, Pagano $\mathrm{M}$, et al. Influence of psychiatric comorbidity on recovery and recurrence in generalized anxiety disorder, social phobia, and panic disorder: a 12-year prospective study. Am J Psychiatry. (2005) 162:1179-87. doi: 10.1176/appi.ajp.162.6.1179

9. Roy-Byrne P. Treatment-refractory anxiety; definition, risk factors, and treatment challenges. Dialogues Clin Neurosci. (2015) 17:191-206. doi: 10.31887/DCNS.2015.17.2/proybyrne

10. American Psychiatric Association. Diagnostic and Statistical Manual of Mental Disorders. 5th ed. Washington, DC (2013).

11. Anttila V, Bulik-Sullivan B, Finucane HK, Walters RK, Bras J, Duncan L, et al. Analysis of shared heritability in common disorders of the brain. Science. (2018) 360:6395. doi: 10.1126/science.aap8757 
12. Sartori SB, Singewald N. Novel pharmacological targets in drug development for the treatment of anxiety and anxiety-related disorders. Pharmacol Ther. (2019) 204:107402. doi: 10.1016/j.pharmthera.2019.107402

13. Bandelow B, Reitt M, Röver C, Michaelis S, Görlich Y, Wedekind D. Efficacy of treatments for anxiety disorders: a meta-analysis. Int Clin Psychopharmacol. (2015) 30:183-92. doi: 10.1097/YIC.0000000000000078

14. American Psychiatric Association. Practice Guideline for the Treatment of Patients with Panic Disorder. Washington, DC (2009).

15. National Institute for Health and Care Excellence (NICE). Generalised Anxiety Disorder and Panic Disordr in Adults: Management. Available online at: https://www.nice.org.uk/guidance/cg113 (accessed November 13, 2020).

16. National Institute for Health and Care Excellence (NICE). Social Anxiety Disorder: Recognition, Assessment and Treatment. Available online at: https:// www.nice.org.uk/guidance/cg159 (accessed November 13, 2020).

17. He H, Xiang Y, Gao F, Bai L, Gao F, Fan Y, et al. Comparative efficacy and acceptability of first-line drugs for the acute treatment of generalized anxiety disorder in adults: a network meta-analysis. J Psychiatr Res. (2019) 118:21-30. doi: 10.1016/j.jpsychires.2019.08.009

18. Dragioti E, Solmi M, Favaro A, Fusar-Poli P, Dazzan P, Thompson $\mathrm{T}$, et al. Association of antidepressant use with adverse health outcomes: a systematic umbrella review. JAMA Psychiatry. (2019) 76:1241-55. doi: 10.1001/jamapsychiatry.2019.2859

19. Sinclair LI, Christmas DM, Hood SD, Potokar JP, Robertson A, Isaac A, et al. Antidepressant-induced jitteriness/anxiety syndrome: systematic review. $\mathrm{Br}$ J Psychiatry. (2009) 194:483-90. doi: 10.1192/bjp.bp.107.048371

20. Bakker A, Van Balkom A, Spinhoven P. SSRIs vs. TCAs in the treatment of panic disorder: a meta-analysis. Acta Psychiatr Scand. (2002) 106:1637. doi: 10.1034/j.1600-0447.2002.02255.x

21. Curtiss J, Andrews L, Davis M, Smits J, Hofmann SG. A meta-analysis of pharmacotherapy for social anxiety disorder: an examination of efficacy, moderators, and mediators. Expert Opin Pharmacother. (2017) 18:24351. doi: 10.1080/14656566.2017.1285907

22. Chessick CA, Allen MH, Thase M, Batista Miralha da Cunha AB, Kapczinski FF, de Lima MS, et al. Azapirones for generalized anxiety disorder. Cochrane Database Syst Rev. (2006) 2006:Cd006115. doi: 10.1002/14651858.CD 006115

23. Imai H, Tajika A, Chen P, Pompoli A, Guaiana G, Castellazzi M, et al. Azapirones versus placebo for panic disorder in adults. Cochrane Database Syst Rev. (2014) 2014:Cd010828. doi: 10.1002/14651858.CD010828.pub2

24. Rissardo JP, Caprara ALF. Buspirone-associated movement disorder: a literature review. Prague Med Rep. (2020) 121:524. doi: 10.14712/23362936.2020.1

25. Landén M, Eriksson E, Agren H, Fahlén T. Effect of buspirone on sexual dysfunction in depressed patients treated with selective serotonin reuptake inhibitors. J Clin Psychopharmacol. (1999) 19:26871. doi: 10.1097/00004714-199906000-00012

26. Moll JL, Brown CS. The use of monoamine pharmacological agents in the treatment of sexual dysfunction: evidence in the literature. J Sexual Med. (2011) 8:956-70. doi: 10.1111/j.1743-6109.2010.02190.x

27. Croom KF, Perry CM, Plosker GL. Mirtazapine: a review of its use in major depression and other psychiatric disorders. CNS Drugs. (2009) 23:42752. doi: 10.2165/00023210-200923050-00006

28. Ribeiro L, Busnello JV, Kauer-Sant'Anna M, Madruga M, Quevedo J, Busnello EA, et al. Mirtazapine versus fluoxetine in the treatment of panic disorder. Braz J Med Biol Res. (2001) 34:1303-7. doi: 10.1590/S0100-879X2001001000010

29. Muehlbacher M, Nickel MK, Nickel C, Kettler C, Lahmann C, Pedrosa Gil F, et al. Mirtazapine treatment of social phobia in women: a randomized, double-blind, placebo-controlled study. J Clin Psychopharmacol. (2005) 25:580-3. doi: 10.1097/01.jcp.0000186871.04984.8d

30. Schutters SI, Van Megen HJ, Van Veen JF, Denys DA, Westenberg HG. Mirtazapine in generalized social anxiety disorder: a randomized, doubleblind, placebo-controlled study. Int Clin Psychopharmacol. (2010) 25:3024. doi: 10.1097/YIC.0b013e32833a4d71

31. Trivedi MH, Rush AJ, Carmody TJ, Donahue RM, Bolden-Watson C, Houser TL, et al. Do bupropion SR and sertraline differ in their effects on anxiety in depressed patients? J Clin Psychiatry. (2001) 62:77681. doi: 10.4088/JCP.v62n1005
32. Papakostas GI, Trivedi MH, Alpert JE, Seifert CA, Krishen A, Goodale EP, et al. Efficacy of bupropion and the selective serotonin reuptake inhibitors in the treatment of anxiety symptoms in major depressive disorder: a metaanalysis of individual patient data from 10 double-blind, randomized clinical trials. J Psychiatr Res. (2008) 42:134-40. doi: 10.1016/j.jpsychires.2007.05.012

33. Papakostas GI, Stahl SM, Krishen A, Seifert CA, Tucker VL, Goodale EP, et al. Efficacy of bupropion and the selective serotonin reuptake inhibitors in the treatment of major depressive disorder with high levels of anxiety (anxious depression): a pooled analysis of 10 studies. J Clin Psychiatry. (2008) 69:1287-92. doi: 10.4088/JCP.v69n0812

34. Bystritsky A, Kerwin L, Feusner JD, Vapnik T. A pilot controlled trial of bupropion XL versus escitalopram in generalized anxiety disorder. Psychopharmacol Bull. (2008) 41:46-51.

35. Sheehan DV, Davidson J, Manschreck T, Van Wyck Fleet J. Lack of efficacy of a new antidepressant (bupropion) in the treatment of panic disorder with phobias. J Clin Psychopharmacol. (1983) 3:2831. doi: 10.1097/00004714-198302000-00006

36. Simon NM, Emmanuel N, Ballenger J, Worthington JJ, Kinrys G, Korbly NB, et al. Bupropion sustained release for panic disorder. Psychopharmacol Bull. (2003) 37:66.

37. Papp LA, Coplan JD, Martinez JM, de Jesus M, Gorman JM. Efficacy of open-label nefazodone treatment in patients with panic disorder. J Clin Psychopharmacol. (2000) 20:5446. doi: 10.1097/00004714-200010000-00009

38. Bystritsky A, Rosen R, Suri R, Vapnik T. Pilot open-label study of nefazodone in panic disorder. Depress Anxiety. (1999) 10:1379. doi: 10.1002/(SICI)1520-6394(1999)10:3<137::AID-DA8 > 3.0.CO;2-7

39. DeMartinis NA, Schweizer E, Rickels K. An open-label trial of nefazodone in high comorbidity panic disorder. J Clin Psychiatry. (1996) 57:245-8.

40. Hedges DW, Reimherr FW, Strong RE, Halls CH, Rust C. An open trial of nefazodone in adult patients with generalized anxiety disorder. Psychopharmacol Bull. (1996) 32:671-6.

41. Van Ameringen M, Mancini C, Oakman J, Walker J, Kjernisted K, Chokka $\mathrm{P}$, et al. Nefazodone in the treatment of generalized social phobia: a randomized, placebo-controlled trial. J Clin Psychiatry. (2007) 68:28895. doi: 10.4088/JCP.v68n0215

42. Agarwal SD, Landon BE. Patterns in outpatient benzodiazepine prescribing in the United States. JAMA Netw Open. (2019) 2:e187399. doi: 10.1001/jamanetworkopen.2018.7399

43. Torres-Bondia F, de Batlle J, Galván L, Buti M, Barbé F, Piñol-Ripoll G. Trends in the consumption rates of benzodiazepines and benzodiazepinerelated drugs in the health region of Lleida from 2002 to 2015. BMC Public Health. (2020) 20:818. doi: 10.1186/s12889-020-08984-z

44. Balon R, Starcevic V. Role of benzodiazepines in anxiety disorders. Adv Exp Med Biol. (2020) 1191:367-88. doi: 10.1007/978-981-32-9705-0_20

45. Moore N, Pariente A, Bégaud B. Why are benzodiazepines not yet controlled substances? JAMA Psychiatry. (2015) 72:1101. doi: 10.1001/jamapsychiatry.2014.2190

46. Gomez AF, Barthel AL, Hofmann SG. Comparing the efficacy of benzodiazepines and serotonergic anti-depressants for adults with generalized anxiety disorder: a meta-analytic review. Expert Opin Pharmacother. (2018) 19:883-94. doi: 10.1080/14656566.2018.1472767

47. Offidani E, Guidi J, Tomba E, Fava GA. Efficacy and tolerability of benzodiazepines versus antidepressants in anxiety disorders: a systematic review and meta-analysis. Psychother Psychosom. (2013) 82:355-62. doi: 10.1159/000353198

48. Shinfuku M, Kishimoto T, Uchida H, Suzuki T, Mimura M, Kikuchi T. Effectiveness and safety of long-term benzodiazepine use in anxiety disorders: a systematic review and meta-analysis. Int Clin Psychopharmacol. (2019) 34:211-21. doi: 10.1097/YIC.0000000000000276

49. Osler M, Jørgensen MB. Associations of benzodiazepines, Z-drugs, and other anxiolytics with subsequent dementia in patients with affective disorders: a nationwide cohort and nested case-control study. Am J Psychiatry. (2020) 177:497-505. doi: 10.1176/appi.ajp.2019.19030315

50. Lim B, Sproule BA, Zahra Z, Sunderji N, Kennedy SH, Rizvi SJ. Understanding the effects of chronic benzodiazepine use in depression: a focus on neuropharmacology. Int Clin Psychopharmacol. (2020) 35:24353. doi: 10.1097/YIC.0000000000000316 
51. Mula M, Pini S, Cassano GB. The role of anticonvulsant drugs in anxiety disorders: a critical review of the evidence. J Clin Psychopharmacol. (2007) 27:263-72. doi: 10.1097/jcp.0b013e318059361a

52. Generoso MB, Trevizol AP, Kasper S, Cho HJ, Cordeiro Q, Shiozawa P. Pregabalin for generalized anxiety disorder: an updated systematic review and meta-analysis. Int Clin Psychopharmacol. (2017) 32:4955. doi: 10.1097/YIC.0000000000000147

53. Kawalec P, Cierniak A, Pilc A, Nowak G. Pregabalin for the treatment of social anxiety disorder. Expert Opin Investig Drugs. (2015) 24:58594. doi: 10.1517/13543784.2014.979283

54. Greist JH, Liu-Dumaw M, Schweizer E, Feltner D. Efficacy of pregabalin in preventing relapse in patients with generalized social anxiety disorder: results of a double-blind, placebo-controlled 26-week study. Int Clin Psychopharmacol. (2011) 26:243-51. doi: 10.1097/YIC.0b013e3283491fd5

55. Pande AC, Feltner DE, Jefferson JW, Davidson JR, Pollack M, Stein MB, et al. Efficacy of the novel anxiolytic pregabalin in social anxiety disorder: a placebo-controlled, multicenter study. J Clin Psychopharmacol. (2004) 24:141-9. doi: 10.1097/01.jcp.0000117423.05703.e7

56. Feltner DE, Liu-Dumaw M, Schweizer E, Bielski R. Efficacy of pregabalin in generalized social anxiety disorder: results of a double-blind, placebocontrolled, fixed-dose study. Int Clin Psychopharmacol. (2011) 26:21320. doi: 10.1097/YIC.0b013e32834519bd

57. Evoy KE, Covvey JR, Peckham AM, Ochs L, Hultgren KE. Reports of gabapentin and pregabalin abuse, misuse, dependence, or overdose: an analysis of the Food And Drug Administration Adverse Events Reporting System (FAERS). Res Social Adm Pharm. (2019) 15:9538. doi: 10.1016/j.sapharm.2018.06.018

58. Schifano F, Chiappini S. Pregabalin: a range of misuse-related unanswered questions. CNS Neurosci Ther. (2019) 25:659-60. doi: 10.1111/cns.13115

59. Nahar LK, Murphy KG, Paterson S. Misuse and mortality related to gabapentin and pregabalin are being under-estimated: a twoyear post-mortem population study. J Anal Toxicol. (2019) 43:564-70. doi: 10.1093/jat/bkz036

60. Ahmed S, Stanciu CN, Kotapati PV, Ahmed R, Bhivandkar S, Khan AM, et al. Effectiveness of gabapentin in reducing cravings and withdrawal in alcohol use disorder: a meta-analytic review. Prim Care Companion CNS Disord. (2019) 21:19r02465. doi: 10.4088/PCC.19r02465

61. Ahmed S, Bachu R, Kotapati P, Adnan M, Ahmed R, Farooq U, et al. Use of gabapentin in the treatment of substance use and psychiatric disorders: a systematic review. Front Psychiatry. (2019) 10:228. doi: 10.3389/fpsyt.2019.00228

62. Pande AC, Pollack MH, Crockatt J, Greiner M, Chouinard G, Lydiard RB, et al. Placebo-controlled study of gabapentin treatment of panic disorder. J Clin Psychopharmacol. (2000) 20:467-71. doi: 10.1097/00004714-200008000-00011

63. de-Paris F, Sant'Anna MK, Vianna MR, Barichello T, Busnello JV, Kapczinski F, et al. Effects of gabapentin on anxiety induced by simulated public speaking. J Psychopharmacol. (2003) 17:184-8. doi: 10.1177/0269881103017002006

64. Smith RV, Havens JR, Walsh SL. Gabapentin misuse, abuse and diversion: a systematic review. Addiction. (2016) 111:1160-74. doi: 10.1111/add.13324

65. Schmitt U, Lüddens H, Hiemke C. Anxiolytic-like effects of acute and chronic GABA transporter inhibition in rats. J Neural Transm. (2002) 109:87180. doi: $10.1007 / \mathrm{s} 007020200071$

66. Pollack MH, Tiller J, Xie F, Trivedi MH. Tiagabine in adult patients with generalized anxiety disorder: results from 3 randomized, double-blind, placebo-controlled, parallel-group studies. J Clin Psychopharmacol. (2008) 28:308-16. doi: 10.1097/JCP.0b013e318172b45f

67. Zwanzger P, Eser D, Nothdurfter C, Baghai TC, Möller HJ, Padberg F, et al. Effects of the GABA-reuptake inhibitor tiagabine on panic and anxiety in patients with panic disorder. Pharmacopsychiatry. (2009) 42:2669. doi: 10.1055/s-0029-1241798

68. Urbano MR, Spiegel DR, Laguerta N, Shrader CJ, Rowe DF, Hategan LF. Gabapentin and tiagabine for social anxiety: a randomized, double-blind, crossover study of 8 adults. Prim Care Companion J Clin Psychiatry. (2009) 11:123. doi: 10.4088/PCC.08100641

69. Mirza NR, Bright JL, Stanhope KJ, Wyatt A, Harrington NR. Lamotrigine has an anxiolytic-like profile in the rat conditioned emotional response test of anxiety: a potential role for sodium channels? Psychopharmacology. (2005) 180:159-68. doi: 10.1007/s00213-005-2146-1

70. Masdrakis VG, Papadimitriou GN, Oulis P. Lamotrigine administration in panic disorder with agoraphobia. Clin Neuropharmacol. (2010) 33:1268. doi: 10.1097/WNF.0b013e3181d4c1f6

71. Van Ameringen M, Mancini C, Pipe B, Bennett M. Antiepileptic drugs in the treatment of anxiety disorders: role in therapy. Drugs. (2004) 64:2199220. doi: 10.2165/00003495-200464190-00004

72. Aliyev NA, Aliyev ZN. Valproate (depakine-chrono) in the acute treatment of outpatients with generalized anxiety disorder without psychiatric comorbidity: randomized, double-blind placebo-controlled study. Eur Psychiatry. (2008) 23:109-14. doi: 10.1016/j.eurpsy.2007. 08.001

73. Kinrys G, Pollack MH, Simon NM, Worthington JJ, Nardi AE, Versiani M. Valproic acid for the treatment of social anxiety disorder. Int Clin Psychopharmacol. (2003) 18:16972. doi: 10.1097/00004850-200305000-00008

74. Stein MB, Ravindran LN, Simon NM, Liebowitz MR, Khan A, BrawmanMintzer O, et al. Levetiracetam in generalized social anxiety disorder: a double-blind, randomized controlled trial. J Clin Psychiatry. (2010) 71:62731. doi: 10.4088/JCP.08m04949gre

75. Zhang W, Connor KM, Davidson JR. Levetiracetam in social phobia: a placebo controlled pilot study. J Psychopharmacol. (2005) 19:5513. doi: 10.1177/0269881105056526

76. Guaiana G, Barbui C, Cipriani A. Hydroxyzine for generalised anxiety disorder. Cochrane Database Syst Rev. (2010) 2010:Cd006815. doi: 10.1002/14651858.CD006815.pub2

77. Steenen SA, van Wijk AJ, van der Heijden GJ, van Westrhenen R, de Lange J, de Jongh A. Propranolol for the treatment of anxiety disorders: systematic review and meta-analysis. J Psychopharmacol. (2016) 30:12839. doi: $10.1177 / 0269881115612236$

78. Davidson JR. Pharmacotherapy of social anxiety disorder: what does the evidence tell us? J Clin Psychiatry. (2006) 67(Suppl. 12):20-6.

79. Charney DS, Heninger GR. Abnormal regulation of noradrenergic function in panic disorders. Effects of clonidine in healthy subjects and patients with agoraphobia and panic disorder. Arch Gen Psychiatry. (1986) 43:104254. doi: 10.1001/archpsyc.1986.01800110028005

80. Strawn JR, Compton SN, Robertson B, Albano AM, Hamdani M, Rynn MA. Extended release guanfacine in pediatric anxiety disorders: a pilot, randomized, placebo-controlled trial. J Child Adolesc Psychopharmacol. (2017) 27:29-37. doi: 10.1089/cap.2016.0132

81. Uhde TW, Stein MB, Vittone BJ, Siever LJ, Boulenger JP, Klein E, et al. Behavioral and physiologic effects of short-term and long-term administration of clonidine in panic disorder. Arch Gen Psychiatry. (1989) 46:170-7. doi: 10.1001/archpsyc. 1989.01810020072012

82. Hoehn-Saric R, Merchant AF, Keyser ML, Smith VK. Effects of clonidine on anxiety disorders. Arch Gen Psychiatry. (1981) 38:1278-82. doi: 10.1001/archpsyc.1981.0178 0360094011

83. Bergendahl H, Lönnqvist PA, Eksborg S. Clonidine in paediatric anaesthesia: review of the literature and comparison with benzodiazepines for premedication. Acta Anaesthesiol Scand. (2006) 50:135-43. doi: 10.1111/j.1399-6576.2006.00940.x

84. Maher AR, Maglione M, Bagley S, Suttorp M, Hu JH, Ewing B, et al. Efficacy and comparative effectiveness of atypical antipsychotic medications for offlabel uses in adults: a systematic review and meta-analysis. JAMA. (2011) 306:1359-69. doi: 10.1001/jama.2011.1360

85. Depping AM, Komossa K, Kissling W, Leucht S. Second-generation antipsychotics for anxiety disorders. Cochrane Database Syst Rev. (2010) 2010:Cd008120. doi: 10.1002/14651858.CD008120.pub2

86. LaLonde CD, Van Lieshout RJ. Treating generalized anxiety disorder with second generation antipsychotics: a systematic review and meta-analysis. J Clin Psychopharmacol. (2011) 31:326-33. doi: 10.1097/JCP.0b013e31821b2b3f

87. Katzman MA, Bleau P, Blier P, Chokka P, Kjernisted K, Van Ameringen M, et al. Canadian clinical practice guidelines for the management of anxiety, posttraumatic stress and obsessive-compulsive disorders. BMC Psychiatry. (2014) 14(Suppl. 1):S1. doi: 10.1186/1471-244X-14-S1-S1 
88. Perna G, Alessandra A, Raffaele B, Elisa M, Giuseppina D, Paolo C, et al. Is there room for second-generation antipsychotics in the pharmacotherapy of panic disorder? A systematic review based on PRISMA guidelines. Int J Mol Sci. (2016) 17:551. doi: 10.3390/ijms17040551

89. Griebel G, Holmes A. 50 years of hurdles and hope in anxiolytic drug discovery. Nat Rev Drug Discov. (2013) 12:667-87. doi: 10.1038/nrd4075

90. Zareifopoulos N, Dylja I. Efficacy and tolerability of vilazodone for the acute treatment of generalized anxiety disorder: a meta-analysis. Asian J Psychiatr. (2017) 26:115-22. doi: 10.1016/j.ajp.2017.01.016

91. Slee A, Nazareth I, Bondaronek P, Liu Y, Cheng Z, Freemantle N. Pharmacological treatments for generalised anxiety disorder: a systematic review and network meta-analysis. Lancet. (2019) 393:768-77. doi: 10.1016/S0140-6736(18)31793-8

92. Schneier FR, Moskow DM, Choo TH, Galfalvy H, Campeas R, Sanchez-Lacay A. A randomized controlled pilot trial of vilazodone for adult separation anxiety disorder. Depress Anxiety. (2017) 34:1085-95. doi: 10.1002/da.22693

93. Careri JM, Draine AE, Hanover R, Liebowitz MR. A 12-week doubleblind, placebo-controlled, flexible-dose trial of vilazodone in generalized social anxiety disorder. Prim Care Companion CNS Disord. (2015) 17. doi: 10.4088/PCC.15m01831

94. Clayton AH, Durgam S, Tang X, Chen C, Ruth A, Gommoll C. Characterizing sexual function in patients with generalized anxiety disorder: a pooled analysis of three vilazodone studies. Neuropsychiatr Dis Treat. (2016) 12:1467-76. doi: 10.2147/NDT.S103408

95. Yee A, Ng CG, Seng LH. Vortioxetine treatment for anxiety disorder: a meta-analysis study. Curr Drug Targets. (2018) 19:1412-23. doi: 10.2174/1389450118666171117131151

96. Bidzan L, Mahableshwarkar AR, Jacobsen P, Yan M, Sheehan DV. Vortioxetine (Lu AA21004) in generalized anxiety disorder: results of an 8-week, multinational, randomized, double-blind, placebo-controlled clinical trial. Eur Neuropsychopharmacol. (2012) 22:847-57. doi: 10.1016/j.euroneuro.2012.07.012

97. Baldwin DS, Loft H, Florea I. Lu AA21004, a multimodal psychotropic agent, in the prevention of relapse in adult patients with generalized anxiety disorder. Int Clin Psychopharmacol. (2012) 27:197-207. doi: 10.1097/YIC.0b013e3283530ad7

98. Qin B, Huang G, Yang Q, Zhao M, Chen H, Gao W, et al. Vortioxetine treatment for generalised anxiety disorder: a meta-analysis of anxiety, quality of life and safety outcomes. BMJ Open. (2019) 9:e033161. doi: 10.1136/bmjopen-2019-033161

99. Shah A, Northcutt J. An open-label, flexible dose adaptive study evaluating the efficacy of vortioxetine in subjects with panic disorder. Ann Genrl Psychiatry. (2018) 17:1-7. doi: 10.1186/s12991-018-0190-6

100. Celada P, Bortolozzi A, Artigas F. Serotonin 5-HT 1A receptors as targets for agents to treat psychiatric disorders: rationale and current status of research. CNS Drugs. (2013) 27:703-16. doi: 10.1007/s40263-0130071-0

101. Pecknold JC, Luthe L, Scott-Fleury MH, Jenkins S. Gepirone and the treatment of panic disorder: an open study. J Clin Psychopharmacol. (1993) 13:145-9. doi: 10.1097/00004714-199304000-00009

102. Kaur Gill A, Bansal Y, Bhandari R, Kaur S, Kaur J, Singh R, et al. Gepirone hydrochloride: a novel antidepressant with 5-HT1A agonistic properties. Drugs Today. (2019) 55:423-37. doi: 10.1358/dot.2019.55.7.2958474

103. Fabre-Kramer Pharmaceuticals I. Travivo ${ }^{T M}$ for Generalized Anxiety Disorder. Available online at: https://www.fabrekramer.com/products/ tgfk07ad/tgfk07ad/ (accessed November 13, 2020).

104. Nishitsuji K, To H, Murakami Y, Kodama K, Kobayashi D, Yamada T, et al. Tandospirone in the treatment of generalised anxiety disorder and mixed anxiety-depression : results of a comparatively high dosage trial. Clin Drug Investig. (2004) 24:121-6. doi: 10.2165/00044011-20042402000007

105. Lin J, Su Y, Wang C, Yang F, Xu Y, Yuan Y, et al. Effects of tandospirone augmentation in major depressive disorder patients with high anxiety: a multicenter, randomized, parallel-controlled, open-label study. J Psychiatr Res. (2018) 99:104-10. doi: 10.1016/j.jpsychires.2018.01.020

106. Rickels K, Mathew S, Banov MD, Zimbroff DL, Oshana S, Parsons EC, et al. Effects of PRX-00023, a novel, selective serotonin 1A receptor agonist on measures of anxiety and depression in generalized anxiety disorder: results of a double-blind, placebo-controlled trial. J Clin Psychopharmacol. (2008) 28:235-9. doi: 10.1097/JCP.0b013e31816774de

107. Fabre-Kramer Pharmaceuticals I. FKW00GA. Available online at: https:// www.fabrekramer.com/products/tgw00aa/ (accessed November 13, 2020).

108. Wesołowska A, Nikiforuk A, Stachowicz K. Anxiolytic-like and antidepressant-like effects produced by the selective 5-HT6 receptor antagonist SB-258585 after intrahippocampal administration to rats. Behav Pharmacol. (2007) 18:439-46. doi: 10.1097/FBP.0b013e3282d28f9c

109. Ivachtchenko AV, Lavrovsky Y, Okun I. AVN-101: a multi-target drug candidate for the treatment of CNS disorders. J Alzheimers Dis. (2016) 53:583-620. doi: 10.3233/JAD-151146

110. Freeman AM 3rd, Westphal JR, Norris GT, Roggero BA, Webb $\mathrm{PB}$, Freeman KL, et al. Efficacy of ondansetron in the treatment of generalized anxiety disorder. Depress Anxiety. (1997) 5:1401. doi: 10.1002/(SICI)1520-6394(1997)5:3<140::AID-DA7>3.0.CO;2-I

111. Schneier FR, Garfinkel R, Kennedy B, Campeas R, Fallon B, Marshall R, et al. Ondansetron in the treatment of panic disorder. Anxiety. (1996) 2:199202. doi: 10.1002/(SICI)1522-7154(1996)2:4<199::AID-ANXI7>3.0.CO;2-J

112. MacIsaac SE, Carvalho AF, Cha DS, Mansur RB, McIntyre RS. The mechanism, efficacy, and tolerability profile of agomelatine. Expert Opin Pharmacother. (2014) 15:259-74. doi: 10.1517/14656566.2014.862233

113. Stein DJ, Khoo JP, Ahokas A, Jarema M, Van Ameringen M, Vavrusova L, et al. 12-week double-blind randomized multicenter study of efficacy and safety of agomelatine $(25-50 \mathrm{mg} /$ day $)$ versus escitalopram (10-20 $\mathrm{mg} /$ day $)$ in out-patients with severe generalized anxiety disorder. Eur Neuropsychopharmacol. (2018) 28:970-9. doi: 10.1016/j.euroneuro.2018.05.006

114. Stein DJ, Ahokas AA, de Bodinat C. Efficacy of agomelatine in generalized anxiety disorder: a randomized, double-blind, placebo-controlled study. J Clin Psychopharmacol. (2008) 28:561-6. doi: 10.1097/JCP.0b013e31818 4 ff5b

115. Stein DJ, Ahokas A, Márquez MS, Höschl C, Oh KS, Jarema $M$, et al. Agomelatine in generalized anxiety disorder: an active comparator and placebo-controlled study. J Clin Psychiatry. (2014) 75:362-8. doi: 10.4088/JCP.13m08433

116. Stein DJ, Ahokas A, Jarema M, Avedisova AS, Vavrusova L, Chaban O, et al. Efficacy and safety of agomelatine (10 or $25 \mathrm{mg} /$ day) in nondepressed out-patients with generalized anxiety disorder: a 12-week, doubleblind, placebo-controlled study. Eur Neuropsychopharmacol. (2017) 27:52637. doi: 10.1016/j.euroneuro.2017.02.007

117. Stein DJ, Ahokas A, Albarran C, Olivier V, Allgulander C. Agomelatine prevents relapse in generalized anxiety disorder: a 6-month randomized, double-blind, placebo-controlled discontinuation study. J Clin Psychiatry. (2012) 73:1002-8. doi: 10.4088/JCP.11m07493

118. Weston NM, Gibbs D, Bird CIV, Daniel A, Jelen LA, Knight G, et al. Historic psychedelic drug trials and the treatment of anxiety disorders. Depress Anxiety. (2020). doi: 10.1002/da.23065. [Epub ahead of print].

119. Fuentes JJ, Fonseca F, Elices M, Farré M, Torrens M. Therapeutic use of LSD in psychiatry: a systematic review of randomized-controlled clinical trials. Front Psychiatry. (2019) 10:943. doi: 10.3389/fpsyt.2019. 00943

120. Krystal JH, Mathew SJ, D’Souza DC, Garakani A, Gunduz-Bruce $\mathrm{H}$, Charney DS. Potential psychiatric applications of metabotropic glutamate receptor agonists and antagonists. CNS Drugs. (2010) 24:66993. doi: 10.2165/11533230-000000000-00000

121. Bergink V, Westenberg HG. Metabotropic glutamate II receptor agonists in panic disorder: a double blind clinical trial with LY354740. Int Clin Psychopharmacol. (2005) 20:2913. doi: 10.1097/00004850-200511000-00001

122. Dunayevich E, Erickson J, Levine L, Landbloom R, Schoepp DD, Tollefson GD. Efficacy and tolerability of an mGlu2/3 agonist in the treatment of generalized anxiety disorder. Neuropsychopharmacology. (2008) 33:160310. doi: 10.1038/sj.npp.1301531

123. Kent JM, Daly E, Kezic I, Lane R, Lim P, De Smedt H, et al. Efficacy and safety of an adjunctive mGlu2 receptor positive allosteric modulator to a SSRI/SNRI in anxious depression. Prog Neuropsychopharmacol Biol Psychiatry. (2016) 67:66-73. doi: 10.1016/j.pnpbp.2016.01.009 
124. Wan LB, Levitch CF, Perez AM, Brallier JW, Iosifescu DV, Chang LC, et al. Ketamine safety and tolerability in clinical trials for treatment-resistant depression. J Clin Psychiatry. (2015) 76:247-52. doi: 10.4088/JCP.13m08852

125. Newport DJ, Carpenter LL, McDonald WM, Potash JB, Tohen M, Nemeroff CB. Ketamine and other NMDA antagonists: early clinical trials and possible mechanisms in depression. Am J Psychiatry. (2015) 172:95066. doi: 10.1176/appi.ajp.2015.15040465

126. Murrough JW, Iosifescu DV, Chang LC, Al Jurdi RK, Green CE, Perez AM, et al. Antidepressant efficacy of ketamine in treatment-resistant major depression: a two-site randomized controlled trial. Am J Psychiatry. (2013) 170:1134-42. doi: 10.1176/appi.ajp.2013.13030392

127. Fava M, Freeman MP, Flynn M, Judge H, Hoeppner BB, Cusin C, et al. Double-blind, placebo-controlled, dose-ranging trial of intravenous ketamine as adjunctive therapy in treatment-resistant depression (TRD). Mol Psychiatry. (2020) 25:1592-603. doi: 10.1038/s41380-018-0256-5

128. Singh JB, Fedgchin M, Daly EJ, De Boer P, Cooper K, Lim P, et al. A doubleblind, randomized, placebo-controlled, dose-frequency study of intravenous ketamine in patients with treatment-resistant depression. Am J Psychiatry. (2016) 173:816-26. doi: 10.1176/appi.ajp.2016.16010037

129. Phillips JL, Norris S, Talbot J, Birmingham M, Hatchard T, Ortiz A, et al. Single, repeated, and maintenance ketamine infusions for treatmentresistant depression: a randomized controlled trial. Am J Psychiatry. (2019) 176:401-9. doi: 10.1176/appi.ajp.2018.18070834

130. Murrough JW, Perez AM, Pillemer S, Stern J, Parides MK, aan het Rot M, et al. Rapid and longer-term antidepressant effects of repeated ketamine infusions in treatment-resistant major depression. Biol Psychiatry. (2013) 74:250-6. doi: 10.1016/j.biopsych.2012.06.022

131. Sanacora G, Frye MA, McDonald W, Mathew SJ, Turner MS, Schatzberg AF, et al. A consensus statement on the use of ketamine in the treatment of mood disorders. JAMA Psychiatry. (2017) 74:399-405. doi: 10.1001/jamapsychiatry.2017.0080

132. Papakostas GI, Salloum NC, Hock RS, Jha MK, Murrough JW, Mathew SJ, et al. Efficacy of esketamine augmentation in major depressive disorder: a meta-analysis. J Clin Psychiatry. (2020) 81:19r12889. doi: 10.4088/JCP.19r12889

133. Engin E, Treit D, Dickson CT. Anxiolytic- and antidepressant-like properties of ketamine in behavioral and neurophysiological animal models. Neuroscience. (2009) 161:359-69. doi: 10.1016/j.neuroscience.2009.03.038

134. Irwin SA, Iglewicz A, Nelesen RA, Lo JY, Carr CH, Romero SD, et al. Daily oral ketamine for the treatment of depression and anxiety in patients receiving hospice care: a 28-day open-label proof-of-concept trial. J Palliat Med. (2013) 16:958-65. doi: 10.1089/jpm.2012.0617

135. Glue P, Medlicott NJ, Harland S, Neehoff S, Anderson-Fahey B, Le Nedelec $\mathrm{M}$, et al. Ketamine's dose-related effects on anxiety symptoms in patients with treatment refractory anxiety disorders. J Psychopharmacol. (2017) 31:13025. doi: 10.1177/0269881117705089

136. Glue P, Neehoff SM, Medlicott NJ, Gray A, Kibby G, McNaughton N. Safety and efficacy of maintenance ketamine treatment in patients with treatment-refractory generalised anxiety and social anxiety disorders. $J$ Psychopharmacol. (2018) 32:663-7. doi: 10.1177/0269881118762073

137. Taylor JH, Landeros-Weisenberger A, Coughlin C, Mulqueen J, Johnson JA, Gabriel D, et al. Ketamine for social anxiety disorder: a randomized, placebocontrolled crossover trial. Neuropsychopharmacology. (2018) 43:32533. doi: 10.1038/npp.2017.194

138. Zarate CA Jr, Payne JL, Quiroz J, Sporn J, Denicoff KK, et al. An open-label trial of riluzole in patients with treatment-resistant major depression. Am J Psychiatry. (2004) 161:171-4. doi: 10.1176/appi.ajp.161.1.171

139. Sanacora G, Kendell SF, Levin Y, Simen AA, Fenton LR, Coric V, et al. Preliminary evidence of riluzole efficacy in antidepressant-treated patients with residual depressive symptoms. Biol Psychiatry. (2007) 61:8225. doi: 10.1016/j.biopsych.2006.08.037

140. Mathew SJ, Murrough JW, aan het Rot M, Collins KA, Reich DL, Charney DS. Riluzole for relapse prevention following intravenous ketamine in treatment-resistant depression: a pilot randomized, placebocontrolled continuation trial. Int J Neuropsychopharmacol. (2010) 13:7182. doi: 10.1017/S1461145709000169

141. Sugiyama A, Saitoh A, Iwai T, Takahashi K, Yamada M, Sasaki-Hamada S, et al. Riluzole produces distinct anxiolytic-like effects in rats without the adverse effects associated with benzodiazepines. Neuropharmacology. (2012) 62:2489-98. doi: 10.1016/j.neuropharm.2012.02.012

142. Stutzmann JM, Cintrat P, Laduron PM, Blanchard JC. Riluzole antagonizes the anxiogenic properties of the beta-carboline FG 7142 in rats. Psychopharmacology. (1989) 99:515-9. doi: 10.1007/BF00589901

143. Mathew SJ, Amiel JM, Coplan JD, Fitterling HA, Sackeim HA, Gorman JM. Open-label trial of riluzole in generalized anxiety disorder. Am J Psychiatry. (2005) 162:2379-81. doi: 10.1176/appi.ajp.162.12.2379

144. Mathew SJ, Price RB, Mao X, Smith EL, Coplan JD, Charney DS, et al. Hippocampal $\mathrm{N}$-acetylaspartate concentration and response to riluzole in generalized anxiety disorder. Biol Psychiatry. (2008) 63:8918. doi: 10.1016/j.biopsych.2007.09.012

145. Abdallah CG, Coplan JD, Jackowski A, Sato JR, Mao X, Shungu DC, et al. A pilot study of hippocampal volume and $\mathrm{N}$-acetylaspartate (NAA) as response biomarkers in riluzoletreated patients with GAD. Eur Neuropsychopharmacol. (2013) 23:276-84. doi: 10.1016/j.euroneuro.2012.05.009

146. Myers KM, Carlezon WA Jr, Davis M. Glutamate receptors in extinction and extinction-based therapies for psychiatric illness. Neuropsychopharmacology. (2011) 36:274-93. doi: 10.1038/npp.2010.88

147. Nations KR, Dogterom P, Bursi R, Schipper J, Greenwald S, Zraket D, et al. Examination of Org 26576, an AMPA receptor positive allosteric modulator, in patients diagnosed with major depressive disorder: an exploratory, randomized, double-blind, placebo-controlled trial. J Psychopharmacol. (2012) 26:1525-39. doi: 10.1177/0269881112458728

148. Davis M, Ressler K, Rothbaum BO, Richardson R. Effects of D-cycloserine on extinction: translation from preclinical to clinical work. Biol Psychiatry. (2006) 60:369-75. doi: 10.1016/j.biopsych.2006.03.084

149. Heresco-Levy U, Kremer I, Javitt DC, Goichman R, Reshef A, Blanaru $\mathrm{M}$, et al. Pilot-controlled trial of D-cycloserine for the treatment of post-traumatic stress disorder. Int J Neuropsychopharmacol. (2002) 5:3017. doi: $10.1017 /$ S1461145702003061

150. Bailey J, Papadopoulos A, Lingford-Hughes A, Nutt D. D-Cycloserine and performance under different states of anxiety in healthy volunteers. Psychopharmacology. (2007) 193:579-85. doi: 10.1007/s00213-0070817-9

151. Onur OA, Schlaepfer TE, Kukolja J, Bauer A, Jeung H, Patin A, et al. The Nmethyl-D-aspartate receptor co-agonist $\mathrm{D}$-cycloserine facilitates declarative learning and hippocampal activity in humans. Biol Psychiatry. (2010) 67:1205-11. doi: 10.1016/j.biopsych.2010.01.022

152. Nave AM, Tolin DF, Stevens MC. Exposure therapy, D-cycloserine, and functional magnetic resonance imaging in patients with snake phobia: a randomized pilot study. J Clin Psychiatry. (2012) 73:117986. doi: 10.4088/JCP.11m07564

153. Ori R, Amos $\mathrm{T}$, Bergman $\mathrm{H}$, Soares-Weiser $\mathrm{K}$, Ipser JC, Stein DJ. Augmentation of cognitive and behavioural therapies (CBT) with $\mathrm{d}$ cycloserine for anxiety and related disorders. Cochrane Database Syst Rev. (2015) 2015:CD007803. doi: 10.1002/14651858.CD007803.pub2

154. Mataix-Cols D, Fernández de la Cruz L, Monzani B, Rosenfield D, Andersson E, Pérez-Vigil A, et al. D-cycloserine augmentation of exposurebased cognitive behavior therapy for anxiety, obsessive-compulsive, and posttraumatic stress disorders: a systematic review and metaanalysis of individual participant data. JAMA Psychiatry. (2017) 74:50110. doi: 10.1001/jamapsychiatry.2016.3955

155. Reinecke A, Nickless A, Browning M, Harmer CJ. Neurocognitive processes in d-cycloserine augmented single-session exposure therapy for anxiety: a randomized placebo-controlled trial. Behav Res Therapy. (2020) 129:103607. doi: 10.1016/j.brat.2020.103607

156. Hofmeijer-Sevink MK, Duits P, Rijkeboer MM, Hoogendoorn AW, van Megen HJ, Vulink NC, et al. No effects of D-cycloserine enhancement in exposure with response prevention therapy in panic disorder with agoraphobia: a double-blind, randomized controlled trial. J Clin Psychopharmacol. (2017) 37:531-9. doi: 10.1097/JCP.00000000000 00757

157. Roque AD, Rosenfield D, Smits JAJ, Simon N, Otto MW, Marques L, et al. Does d-cycloserine facilitate the effects of homework compliance on social anxiety symptom reduction? J Anxiety Disord. (2018) 53:8590. doi: 10.1016/j.janxdis.2017.11.004 
158. Hofmann SG, Meuret AE, Smits JA, Simon NM, Pollack MH, Eisenmenger $\mathrm{K}$, et al. Augmentation of exposure therapy with Dcycloserine for social anxiety disorder. Arch Gen Psychiatry. (2006) 63:298-304. doi: 10.1001/archpsyc.63.3.298

159. Guastella AJ, Richardson R, Lovibond PF, Rapee RM, Gaston JE, Mitchell $\mathrm{P}$, et al. A randomized controlled trial of D-cycloserine enhancement of exposure therapy for social anxiety disorder. Biol Psychiatry. (2008) 63:5449. doi: 10.1016/j.biopsych.2007.11.011

160. Smits JAJ, Pollack MH, Rosenfield D, Otto MW, Dowd S, Carpenter J, et al. Dose timing of D-cycloserine to augment exposure therapy for social anxiety disorder: a randomized clinical trial. JAMA Netw Open. (2020) 3:e206777. doi: 10.1001/jamanetworkopen.2020.6777

161. Hofmann SG, Smits JA, Rosenfield D, Simon N, Otto MW, Meuret AE, et al. D-Cycloserine as an augmentation strategy with cognitive-behavioral therapy for social anxiety disorder. Am J Psychiatry. (2013) 170:7518. doi: 10.1176/appi.ajp.2013.12070974

162. Hofmann SG, Papini S, Carpenter JK, Otto MW, Rosenfield D, Dutcher CD, et al. Effect of d-cycloserine on fear extinction training in adults with social anxiety disorder. PLoS ONE. (2019) 14:e0223729. doi: 10.1371/journal.pone.0223729

163. Tart CD, Handelsman PR, Deboer LB, Rosenfield D, Pollack MH, Hofmann SG, et al. Augmentation of exposure therapy with postsession administration of D-cycloserine. J Psychiatr Res. (2013) 47:16874. doi: 10.1016/j.jpsychires.2012.09.024

164. Ressler KJ, Rothbaum BO, Tannenbaum L, Anderson P, Graap K, Zimand E, et al. Cognitive enhancers as adjuncts to psychotherapy: use of D-cycloserine in phobic individuals to facilitate extinction of fear. Arch Gen Psychiatry. (2004) 61:1136-44. doi: 10.1001/archpsyc.61.11.1136

165. Kappelmann N, Suesse M, Steudte-Schmiedgen S, Kaldewaij R, Browning $\mathrm{M}$, Michael T, et al. D-cycloserine as adjunct to brief computerised CBT for spider fear: effects on fear, behaviour, and cognitive biases. $J$ Behav Ther Exp Psychiatry. (2020) 68:101546. doi: 10.1016/j.jbtep.2019. 101546

166. Gutner CA, Weinberger J, Hofmann SG. The effect of D-cycloserine on subliminal cue exposure in spider fearful individuals. Cogn Behav Ther. (2012) 41:335-44. doi: 10.1080/16506073.2012.711770

167. Guastella AJ, Dadds MR, Lovibond PF, Mitchell P, Richardson R. A randomized controlled trial of the effect of D-cycloserine on exposure therapy for spider fear. J Psychiatr Res. (2007) 41:466-71. doi: 10.1016/j.jpsychires.2006.05.006

168. Sani G, Serra G, Kotzalidis GD, Romano S, Tamorri SM, Manfredi G, et al. The role of memantine in the treatment of psychiatric disorders other than the dementias: a review of current preclinical and clinical evidence. CNS Drugs. (2012) 26:663-90. doi: 10.2165/11634390-000000000-00000

169. Feusner JD, Kerwin L, Saxena S, Bystritsky A. Differential efficacy of memantine for obsessive-compulsive disorder vs. generalized anxiety disorder: an open-label trial. Psychopharmacol Bull. (2009) 42:81-93.

170. Jevtović-Todorović V, Todorović SM, Mennerick S, Powell S, Dikranian $\mathrm{K}$, Benshoff $\mathrm{N}$, et al. Nitrous oxide (laughing gas) is an NMDA antagonist, neuroprotectant and neurotoxin. Nat Med. (1998) 4:4603. doi: $10.1038 / \mathrm{nm} 0498-460$

171. Garakani A, Jaffe RJ, Savla D, Welch AK, Protin CA, Bryson EO, et al. Neurologic, psychiatric, and other medical manifestations of nitrous oxide abuse: a systematic review of the case literature. Am J Addict. (2016) 25:35869. doi: 10.1111/ajad.12372

172. Gillman MA. Mini-review: a brief history of nitrous oxide $\left(\mathrm{N}_{2} \mathrm{O}\right)$ use in neuropsychiatry. Curr Drug Res Rev. (2019) 11:12-20. doi: 10.2174/1874473711666181008163107

173. Nagele P, Duma A, Kopec M, Gebara MA, Parsoei A, Walker M, et al. Nitrous oxide for treatment-resistant major depression: a proof-ofconcept trial. Biol Psychiatry. (2015) 78:10-8. doi: 10.1016/j.biopsych.2014. 11.016

174. Gordon D, Heimberg RG, Tellez M, Ismail AI. A critical review of approaches to the treatment of dental anxiety in adults. J Anxiety Disord. (2013) 27:36578. doi: 10.1016/j.janxdis.2013.04.002

175. Atack JR. Preclinical and clinical pharmacology of the GABAA receptor alpha5 subtype-selective inverse agonist alpha5IA. Pharmacol Ther. (2010) 125:11-26. doi: 10.1016/j.pharmthera.2009.09.001
176. Simen A, Whitlock M, Qiu R, Miceli J, Zumpano L, Du Metz M, et al. An 8-week, randomized, phase 2, double-blind, sequential parallelgroup comparison study of two dose levels of the GABAA positive allosteric modulator PF-06372865 compared with placebo as an adjunctive treatment in outpatients with inadequate response to standard of care for generalized anxiety disorder. J Clin Psychopharmacol. (2019) 39:207. doi: 10.1097/JCP.0000000000000997

177. Wise T, Patrick F, Meyer N, Mazibuko N, Oates AE, van der Bijl AHM, et al. Cholinergic modulation of disorder-relevant neural circuits in generalized anxiety disorder. Biol Psychiatry. (2020) 87:908-15. doi: 10.1016/j.biopsych.2019.12.013

178. Prevot TD, Li G, Vidojevic A, Misquitta KA, Fee C, Santrac A, et al. Novel benzodiazepine-like ligands with various anxiolytic, antidepressant, or pro-cognitive profiles. Mol Neuropsychiatry. (2019) 5:84-97. doi: 10.1159/000496086

179. Sage Therapeutics Announces Clinical Updates and Progress Across Neuroscience Pipeline During "Sage FutureCast" [Press Release]. (2019). https://investor.sagerx.com/news-releases/news-release-details/sage-

therapeutics-announces-clinical-updates-and-progress-across (accessed November 13, 2020).

180. Hoffmann E, Nomikos GG, Kaul I, Raines S, Wald J, Bullock A, et al. SAGE-217, a novel GABA(A) receptor positive allosteric modulator: clinical pharmacology and tolerability in randomized phase i dose-finding studies. Clin Pharmacokinet. (2020) 59:111-20. doi: 10.1007/s40262-019-00801-0

181. Macdonald K, Feifel D. Helping oxytocin deliver: considerations in the development of oxytocin-based therapeutics for brain disorders. Front Neurosci. (2013) 7:35. doi: 10.3389/fnins.2013.00035

182. Di Simplicio M, Massey-Chase R, Cowen PJ, Harmer CJ. Oxytocin enhances processing of positive versus negative emotional information in healthy male volunteers. J Psychopharmacol. (2009) 23:241-8. doi: 10.1177/0269881108095705

183. Naja WJ, Aoun MP. Oxytocin and anxiety disorders: translational and therapeutic aspects. Curr Psychiatry Rep. (2017) 19:67. doi: 10.1007/s11920-017-0819-1

184. Acheson DT, Feifel D, Kamenski M, Mckinney R, Risbrough VB. Intranasal oxytocin administration prior to exposure therapy for arachnophobia impedes treatment response. Depression Anxiety. (2015) 32:400-7. doi: 10.1002/da.22362

185. Yoon S, Kim YK. The role of the oxytocin system in anxiety disorders. $A d v$ Exp Med Biol. (2020) 1191:103-20. doi: 10.1007/978-981-32-9705-0_7

186. Gottschalk MG, Domschke K. Oxytocin and anxiety disorders. Curr Top Behav Neurosci. (2018) 35:467-98. doi: 10.1007/7854_2017_25

187. Gorka SM, Fitzgerald DA, Labuschagne I, Hosanagar A, Wood AG, Nathan PJ, et al. Oxytocin modulation of amygdala functional connectivity to fearful faces in generalized social anxiety disorder. Neuropsychopharmacology. (2015) 40:278-86. doi: 10.1038/npp.2014.168

188. Fang A, Treadway MT, Hofmann SG. Working hard for oneself or others: effects of oxytocin on reward motivation in social anxiety disorder. Biol Psychol. (2017) 127:157-62. doi: 10.1016/j.biopsycho.2017.05.015

189. Williams DR, Bürkner PC. Effects of intranasal oxytocin on symptoms of schizophrenia: a multivariate Bayesian meta-analysis. Psychoneuroendocrinology. (2017) 75:14151. doi: 10.1016/j.psyneuen.2016.10.013

190. Bradley ER, Woolley JD. Oxytocin effects in schizophrenia: reconciling mixed findings and moving forward. Neurosci Biobehav Rev. (2017) 80:3656. doi: 10.1016/j.neubiorev.2017.05.007

191. Valstad M, Alvares GA, Egknud M, Matziorinis AM, Andreassen OA, Westlye LT, et al. The correlation between central and peripheral oxytocin concentrations: a systematic review and meta-analysis. Neurosci Biobehav Rev. (2017) 78:117-24. doi: 10.1016/j.neubiorev.2017.04.017

192. Iftikhar K, Siddiq A, Baig SG, Zehra S. Substance P: a neuropeptide involved in the psychopathology of anxiety disorders. Neuropeptides. (2020) 79:101993. doi: 10.1016/j.npep.2019.101993

193. Ebner K, Singewald N. The role of substance $P$ in stress and anxiety responses. Amino Acids. (2006) 31:251-72. doi: 10.1007/s00726-0060335-9

194. Tauscher J, Kielbasa W, Iyengar S, Vandenhende F, Peng X, Mozley D, et al. Development of the 2nd generation neurokinin-1 receptor antagonist 
LY686017 for social anxiety disorder. Eur Neuropsychopharmacol. (2010) 20:80-7. doi: 10.1016/j.euroneuro.2009.10.005

195. Michelson D, Hargreaves R, Alexander R, Ceesay P, Hietala J, Lines C, et al. Lack of efficacy of L-759274, a novel neurokinin 1 (substance P) receptor antagonist, for the treatment of generalized anxiety disorder. Int $J$ Neuropsychopharmacol. (2013) 16:1-11. doi: 10.1017/S1461145712000065

196. Frick A, Ahs F, Linnman C, Jonasson M, Appel L, Lubberink M, et al. Increased neurokinin-1 receptor availability in the amygdala in social anxiety disorder: a positron emission tomography study with [11C]GR205171. Transl Psychiatry. (2015) 5:e597. doi: 10.1038/tp.2015.92

197. Reichmann F, Holzer P. Neuropeptide Y: a stressful review. Neuropeptides. (2016) 55:99-109. doi: 10.1016/j.npep.2015.09.008

198. Mathé AA, Michaneck M, Berg E, Charney DS, Murrough JW. A randomized controlled trial of intranasal neuropeptide y in patients with major depressive disorder. Int J Neuropsychopharmacol. (2020). doi: 10.1093/ijnp/pyaa054. [Epub ahead of print].

199. Sayed S, Van Dam NT, Horn SR, Kautz MM, Parides M, Costi S, et al. A randomized dose-ranging study of neuropeptide $\mathrm{Y}$ in patients with posttraumatic stress disorder. Int J Neuropsychopharmacol. (2017) 21:3-11. doi: 10.1093/ijnp/pyx109

200. An XL, Tai FD. AVP and Glu systems interact to regulate levels of anxiety in BALB/cJ mice. Dongwuxue Yanjiu. (2014) 35:319-25. doi: 10.13918/j.issn.2095-8137.2014.4.319

201. Bleickardt CJ, Mullins DE, Macsweeney CP, Werner BJ, Pond AJ, Guzzi MF, et al. Characterization of the V1a antagonist, JNJ-17308616, in rodent models of anxiety-like behavior. Psychopharmacology. (2009) 202:7118. doi: 10.1007/s00213-008-1354-x

202. Griebel G, Beeské S, Stahl SM. The vasopressin V(1b) receptor antagonist SSR149415 in the treatment of major depressive and generalized anxiety disorders: results from 4 randomized, double-blind, placebo-controlled studies. J Clin Psychiatry. (2012) 73:1403-11. doi: 10.4088/JCP.12m07804

203. Fabio KM, Guillon CD, Lu SF, Heindel ND, Brownstein MJ, Lacey CJ, et al. Pharmacokinetics and metabolism of SRX246: a potent and selective vasopressin 1a antagonist. J Pharm Sci. (2013) 102:203343. doi: $10.1002 /$ jps. 23495

204. Lee RJ, Coccaro EF, Cremers H, McCarron R, Lu SF, Brownstein MJ, et al. A novel V1a receptor antagonist blocks vasopressin-induced changes in the CNS response to emotional stimuli: an fMRI study. Front Syst Neurosci. (2013) 7:100. doi: 10.3389/fnsys.2013.00100

205. Zwanzger P, Domschke K, Bradwejn J. Neuronal network of panic disorder: the role of the neuropeptide cholecystokinin. Depress Anxiety. (2012) 29:76274. doi: 10.1002/da.21919

206. Ballaz SJ, Bourin M, Akil H, Watson SJ. Blockade of the cholecystokinin CCK-2 receptor prevents the normalization of anxiety levels in the rat. Prog Neuropsychopharmacol Biol Psychiatry. (2020) 96:109761. doi: 10.1016/j.pnpbp.2019.109761

207. Risbrough VB, Stein MB. Role of corticotropin releasing factor in anxiety disorders: a translational research perspective. Horm Behav. (2006) 50:55061. doi: 10.1016/j.yhbeh.2006.06.019

208. Bailey JE, Papadopoulos A, Diaper A, Phillips S, Schmidt M, van der Ark P, et al. Preliminary evidence of anxiolytic effects of the $\mathrm{CRF}(1)$ receptor antagonist $\mathrm{R} 317573$ in the $7.5 \% \mathrm{CO}(2)$ proof-of-concept experimental model of human anxiety. J Psychopharmacol. (2011) 25:1199206. doi: $10.1177 / 0269881111400650$

209. Spierling SR, Zorrilla EP. Don't stress about CRF: assessing the translational failures of CRF(1)antagonists. Psychopharmacology. (2017) 234:146781. doi: 10.1007/s00213-017-4556-2

210. Coric V, Feldman HH, Oren DA, Shekhar A, Pultz J, Dockens RC, et al. Multicenter, randomized, double-blind, active comparator and placebo-controlled trial of a corticotropin-releasing factor receptor-1 antagonist in generalized anxiety disorder. Depress Anxiety. (2010) 27:41725. doi: 10.1002/da.20695

211. Schwandt ML, Cortes CR, Kwako LE, George DT, Momenan R, Sinha $\mathrm{R}$, et al. The CRF1 antagonist verucerfont in anxious alcohol-dependent women: translation of neuroendocrine, but not of anti-craving effects. Neuropsychopharmacology. (2016) 41:2818-29. doi: 10.1038/npp.2016.61

212. Kwako LE, Spagnolo PA, Schwandt ML, Thorsell A, George DT, Momenan R, et al. The corticotropin releasing hormone-1 (CRH1) receptor antagonist pexacerfont in alcohol dependence: a randomized controlled experimental medicine study. Neuropsychopharmacology. (2015) 40:105363. doi: $10.1038 / n p p .2014 .306$

213. Grafe LA, Bhatnagar S. Orexins and stress. Front Neuroendocrinol. (2018) 51:132-45. doi: 10.1016/j.yfrne.2018.06.003

214. Sargin D. The role of the orexin system in stress response. Neuropharmacology. (2019) 154:68-78. doi: 10.1016/j.neuropharm.2018. 09.034

215. Johnson PL, Samuels BC, Fitz SD, Federici LM, Hammes N, Early $\mathrm{MC}$, et al. Orexin 1 receptors are a novel target to modulate panic responses and the panic brain network. Physiol Behav. (2012) 107:73342. doi: 10.1016/j.physbeh.2012.04.016

216. Han Y, Yuan K, Zheng Y, Lu L. Orexin receptor antagonists as emerging treatments for psychiatric disorders. Neurosci Bull. (2020) 36:43248. doi: 10.1007/s12264-019-00447-9

217. Eser D, Baghai TC, Schüle C, Nothdurfter C, Rupprecht R. Neuroactive steroids as endogenous modulators of anxiety. Curr Pharm Des. (2008) 14:3525-33. doi: 10.2174/138161208786848838

218. Longone P, di Michele F, D’Agati E, Romeo E, Pasini A, Rupprecht R. Neurosteroids as neuromodulators in the treatment of anxiety disorders. Front Endocrinol. (2011) 2:55. doi: 10.3389/fendo.2011.00055

219. Pinna G, Costa E, Guidotti A. Fluoxetine and norfluoxetine stereospecifically and selectively increase brain neurosteroid content at doses that are inactive on 5-HT reuptake. Psychopharmacology. (2006) 186:362-72. doi: 10.1007/s00213-005-0213-2

220. Lenze EJ, Hershey T, Newcomer JW, Karp JF, Blumberger D, Anger J, et al. Antiglucocorticoid therapy for older adults with anxiety and co-occurring cognitive dysfunction: results from a pilot study with mifepristone. Int $J$ Geriatr Psychiatry. (2014) 29:962-9. doi: 10.1002/gps.4085

221. Liebowitz MR, Salman E, Nicolini H, Rosenthal N, Hanover R, Monti L. Effect of an acute intranasal aerosol dose of PH94B on social and performance anxiety in women with social anxiety disorder. Am J Psychiatry. (2014) 171:675-82. doi: 10.1176/appi.ajp.2014.12101342

222. Liebowitz MR, Hanover R, Draine A, Lemming R, Careri J, Monti L. Effect of as-needed use of intranasal PH94B on social and performance anxiety in individuals with social anxiety disorder. Depression Anxiety. (2016) 33:10819. doi: 10.1002/da.22546

223. Black N, Stockings E, Campbell G, Tran LT, Zagic D, Hall WD, et al. Cannabinoids for the treatment of mental disorders and symptoms of mental disorders: a systematic review and meta-analysis. Lancet Psychiatry. (2019) 6:995-10. doi: 10.1016/S2215-0366(19)30401-8

224. Blessing EM, Steenkamp MM, Manzanares J, Marmar CR. Cannabidiol as a potential treatment for anxiety disorders. Neurotherapeutics. (2015) 12:825-36. doi: 10.1007/s13311-015-0387-1

225. Bergamaschi MM, Queiroz RH, Chagas MH, de Oliveira DC, De Martinis BS, Kapczinski F, et al. Cannabidiol reduces the anxiety induced by simulated public speaking in treatment-naive social phobia patients. Neuropsychopharmacology. (2011) 36:1219-26. doi: 10.1038/npp.2011.6

226. Crippa JA, Derenusson GN, Ferrari TB, Wichert-Ana L, Duran FL, MartinSantos R, et al. Neural basis of anxiolytic effects of cannabidiol (CBD) in generalized social anxiety disorder: a preliminary report. J Psychopharmacol. (2011) 25:121-30. doi: 10.1177/0269881110379283

227. Masataka N. Anxiolytic effects of repeated cannabidiol treatment in teenagers with social anxiety disorders. Front Psychol. (2019) 10:2466. doi: 10.3389/fpsyg.2019.02466

228. Freitas-Ferrari MC, Hallak JE, Trzesniak C, Santos Filho A, Machado-deSousa JP, Chagas MHN, et al. Neuroimaging in social anxiety disorder: a systematic review of the literature. Progr Neuro-Psychopharmacol Biol Psychiatry. (2010) 34:565-80. doi: 10.1016/j.pnpbp.2010.02.028

229. Turna J, Patterson B, Van Ameringen M. Is cannabis treatment for anxiety, mood, and related disorders ready for prime time? Depress Anxiety. (2017) 34:1006-17. doi: 10.1002/da.22664

230. Muller-Vahl KR, Koblenz A, Jobges M, Kolbe H, Emrich HM, Schneider U. Influence of treatment of Tourette syndrome with delta9tetrahydrocannabinol (delta9-THC) on neuropsychological performance. Pharmacopsychiatry. (2001) 34:19-24. doi: 10.1055/s-2001-15191

231. Malik Z, Bayman L, Valestin J, Rizvi-Toner A, Hashmi S, Schey R. Dronabinol increases pain threshold in patients with functional chest pain: a pilot double-blind placebo-controlled trial. Dis Esophagus. (2017) 30:18. doi: $10.1111 /$ dote. 12455 
232. Narang S, Gibson D, Wasan AD, Ross EL, Michna E, Nedeljkovic SS, et al. Efficacy of dronabinol as an adjuvant treatment for chronic pain patients on opioid therapy. J Pain. (2008) 9:254-64. doi: 10.1016/j.jpain.2007.10.018

233. Frank B, Serpell MG, Hughes J, Matthews JN, Kapur D. Comparison of analgesic effects and patient tolerability of nabilone and dihydrocodeine for chronic neuropathic pain: randomised, crossover, double blind study. BMJ. (2008) 336:199-201. doi: 10.1136/bmj.39429.619653.80

234. Pini LA, Guerzoni S, Cainazzo MM, Ferrari A, Sarchielli P, Tiraferri I, et al. Nabilone for the treatment of medication overuse headache: results of a preliminary double-blind, active-controlled, randomized trial. J Headache Pain. (2012) 13:677-84. doi: 10.1007/s10194-012-0490-1

235. Skrabek RQ, Galimova L, Ethans K, Perry D. Nabilone for the treatment of pain in fibromyalgia. J Pain. (2008) 9:16473. doi: $10.1016 /$ j.jpain.2007.09.002

236. Toth C, Mawani S, Brady S, Chan C, Liu C, Mehina E, et al. An enrichedenrolment, randomized withdrawal, flexible-dose, double-blind, placebocontrolled, parallel assignment efficacy study of nabilone as adjuvant in the treatment of diabetic peripheral neuropathic pain. Pain. (2012) 153:207382. doi: 10.1016/j.pain.2012.06.024

237. Glass RM, Uhlenhuth EH, Hartel FW, Schuster CR, Fischman MW. Singledose study of nabilone in anxious volunteers. J Clin Pharmacol. (1981) 21:383S-96. doi: 10.1002/j.1552-4604.1981.tb02618.x

238. Fabre LF, McLendon D. The efficacy and safety of nabilone (a synthetic cannabinoid) in the treatment of anxiety. J Clin Pharmacol. (1981) 21:377S-82S. doi: 10.1002/j.1552-4604.1981.tb02617.x

239. Ilaria RL, Thornby JI, Fann WE. Nabilone, a cannabinol derivative, in the treatment of anxiety neurosis. Curr Ther Res Clin Exp. (1981) 29:943-9.

240. Rog DJ, Nurmikko TJ, Friede T, Young CA. Randomized, controlled trial of cannabis-based medicine in central pain in multiple sclerosis. Neurology. (2005) 65:812-9. doi: 10.1212/01.wnl.0000176753. $45410.8 \mathrm{~b}$

241. Aragona M, Onesti E, Tomassini V, Conte A, Gupta S, Gilio F, et al. Psychopathological and cognitive effects of therapeutic cannabinoids in multiple sclerosis: a double-blind, placebo controlled, crossover study. Clin Neuropharmacol. (2009) 32:41-7. doi: 10.1097/WNF.0B013E3181 633497

242. Lopez-Sendon Moreno JL, Garcia Caldentey J, Trigo Cubillo P, Ruiz Romero C, Garcia Ribas G, Alonso Arias MA, et al. A double-blind, randomized, cross-over, placebo-controlled, pilot trial with Sativex in Huntington's disease. J Neurol. (2016) 263:1390-400. doi: 10.1007/s00415-016-8145-9

243. Yeung KS, Hernandez M, Mao JJ, Haviland I, Gubili J. Herbal medicine for depression and anxiety: a systematic review with assessment of potential psycho-oncologic relevance. Phytotherapy Res. (2018) 32:86591. doi: $10.1002 /$ ptr.6033

244. Singh YN, Singh NN. Therapeutic potential of kava in the treatment of anxiety disorders. CNS Drugs. (2002) 16:73143. doi: 10.2165/00023210-200216110-00002

245. Pittler MH, Ernst E. Kava extract for treating anxiety. Cochrane Database Syst Rev. (2003) 2003:Cd003383. doi: 10.1002/14651858.CD003383

246. Smith K, Leiras C. The effectiveness and safety of Kava Kava for treating anxiety symptoms: a systematic review and analysis of randomized clinical trials. Complement Ther Clin Pract. (2018) 33:107-17. doi: 10.1016/j.ctcp.2018.09.003

247. Ooi SL, Henderson P, Pak SC. Kava for generalized anxiety disorder: a review of current evidence. J Altern Complement Med. (2018) 24:77080. doi: 10.1089/acm.2018.0001

248. Sarris J, McIntyre E. Herbal anxiolytics with sedative actions. In: Camfield D, McIntyre E, Sarris J, editors. Evidence-Based Herbal and Nutritional Treatments for Anxiety in Psychiatric Disorders. Cham: Springer (2017). p. 11-31.
249. Savage K, Firth J, Stough C, Sarris J. GABA-modulating phytomedicines for anxiety: a systematic review of preclinical and clinical evidence. Phytother Res. (2018) 32:3-18. doi: 10.1002/ptr.5940

250. Romero-Cerecero O, Islas-Garduño AL, Zamilpa A, Herrera-Arellano A, Jiménez-Ferrer E, Tortoriello J. Galphimine-B standardized extract versus alprazolam in patients with generalized anxiety disorder: a tenweek, double-blind, randomized clinical trial. BioMed Res Int. (2019) 2019:1037036. doi: 10.1155/2019/1037036

251. Hieu TH, Dibas M, Surya Dila KA, Sherif NA, Hashmi MU, Mahmoud $\mathrm{M}$, et al. Therapeutic efficacy and safety of chamomile for state anxiety, generalized anxiety disorder, insomnia, and sleep quality: a systematic review and meta-analysis of randomized trials and quasi-randomized trials. Phytotherapy Research. (2019) 33:1604-15. doi: 10.1002/ptr.6349

252. Marx W, Lane M, Rocks T, Ruusunen A, Loughman A, Lopresti A, et al. Effect of saffron supplementation on symptoms of depression and anxiety: a systematic review and meta-analysis. Nutr Rev. (2019) 77:55771. doi: 10.1093/nutrit/nuz023

253. Garakani A, Murrough JW, Iosifescu DV. Advances in psychopharmacology for anxiety disorders. FOCUS. (2014) 12:152-62. doi: 10.1176/appi.focus.12.2.152

254. LeDoux JE, Pine DS. Using neuroscience to help understand fear and anxiety: a two-system framework. Am J Psychiatry. (2016) doi: 10.1176/appi.ajp.2016.16030353

255. Craske MG, Stein MB, Eley TC, Milad MR, Holmes A, Rapee RM, et al. Anxiety disorders. Nat Rev Dis Primers. (2017) 3:17024. doi: 10.1038/nrdp.2017.100

256. Chen T-R, Huang H-C, Hsu J-H, Ouyang W-C, Lin K-C. Pharmacological and psychological interventions for generalized anxiety disorder in adults: a network meta-analysis. J Psychiatr Res. (2019) 118:73-83. doi: 10.1016/j.jpsychires.2019.08.014

Conflict of Interest: In the past 5 years, JM has provided consultation services and/or served on advisory boards for Allergan, Boehreinger Ingelheim, Clexio Biosciences, Fortress Biotech, FSV7, Global Medical Education (GME), Impel Neuropharma, Janssen Research and Development, Medavante-Prophase, Novartis, Otsuka, and Sage Therapeutics. JM is named on a patent pending for neuropeptide $\mathrm{Y}$ as a treatment for mood and anxiety disorders and on a patent pending for the use of ezogabine and other KCNQ channel openers to treat depression and related conditions. The Icahn School of Medicine (employer of JM) is named on a patent and has entered into a licensing agreement and will receive payments related to the use of ketamine or esketamine for the treatment of depression. The Icahn School of Medicine is also named on a patent related to the use of ketamine for the treatment of PTSD. JM is not named on these patents and will not receive any payments. In the last 5 years, DI has received consulting honoraria from Alkermes, Axsome, Centers for Psychiatric Excellence, Jazz, Lundbeck, Otsuka, Precision Neuroscience, Sage, Sunovion; he has received research support (through his academic institution) from Alkermes, Astra Zeneca, Brainsway, Litecure, Neosync, Otsuka, Roche, Shire.

The remaining authors declare that the research was conducted in the absence of any commercial or financial relationships that could be construed as a potential conflict of interest.

Copyright (C) 2020 Garakani, Murrough, Freire, Thom, Larkin, Buono and Iosifescu. This is an open-access article distributed under the terms of the Creative Commons Attribution License (CC BY). The use, distribution or reproduction in other forums is permitted, provided the original author(s) and the copyright owner(s) are credited and that the original publication in this journal is cited, in accordance with accepted academic practice. No use, distribution or reproduction is permitted which does not comply with these terms. 